NBER WORKING PAPER SERIES

\title{
THE IMPACT OF LENDING, BORROWING, AND ANTI-SMOKING POLICIES ON CIGARETTE CONSUMPTION BY TEENS
}

\author{
Brett Katzman \\ Sara Markowitz \\ Kerry Anne McGeary \\ Working Paper 8844 \\ http://www.nber.org/papers/w8844 \\ NATIONAL BUREAU OF ECONOMIC RESEARCH \\ 1050 Massachusetts Avenue \\ Cambridge, MA 02138 \\ March 2002
}

The authors would like to thank Jonathan Gruber for providing the data used in this project. In addition, the authors acknowledge the helpful comments and suggestions made by Mike Grossman, Jeff DeSimone, Pinka Chatterji, and seminar participants at CUNY, the University of Miami, and the Southern Economic Association Meetings, Tampa, FL 2001. Special thanks to Yue Xu for exceptional research assistance. The views expressed herein are those of the authors and not necessarily those of the National Bureau of Economic Research.

(C) 2002 by Brett Katzman, Sara Markowitz and Kerry Anne McGeary. All rights reserved. Short sections of text, not to exceed two paragraphs, may be quoted without explicit permission provided that full credit, including $\mathbb{C}$ notice, is given to the source. 
The Impact of Lending, Borrowing, and Anti-Smoking Policies on

Cigarette Consumption by Teens

Brett Katzman, Sara Markowitz and Kerry Anne McGeary

NBER Working Paper No. 8844

March 2002

JEL No. I0

\begin{abstract}
A major factor contributing to smoking initiation and experimentation by teenagers is the ability to "bum" cigarettes. Yet research until now has ignored the impact of a lending/borrowing market on the smoking decisions of teenagers. In this paper, we develop a theoretical model where smoking decisions are determined by an individual's utility maximization process that includes an incentive to lend cigarettes. Predictions from this model are tested using data from the Youth Risk Behavior Surveys that can distinguish between teens who primarily buy and those who primarily bum their cigarettes. We show the ways in which price and restrictions on smoking will impact the decision to buy or bum cigarettes, as well as the impact on the allocation of purchased cigarettes between those self-consumed and those lent to others. Key results indicate that as prices and restrictions increase, teenagers are less likely to be regular smokers who purchase cigarettes and are more likely to consume smaller quantities obtained via the lending market. The basic conclusions are that anti-smoking policies have significant effects on the quantity of cigarettes consumed by teens and that these policies can help reduce the number of teens that escalate from experimental to regular smoking.
\end{abstract}

Brett Katzman

University of Miami

Department of Economics

P.O. Box 248126

Coral Gables, FL 33124

bkatzman@miami.edu
Sara Markowitz

Rutgers University, Newark and NBER

365 Fifth Avenue, 5th Floor

New York, NY 10016

smarkow@newark.rutgers.edu
Kerry Anne McGeary University of Miami

Department of Economics

P.O. Box 248126

Coral Gables, FL 33124

kmcgeary@miami.edu 


\section{Introduction}

Despite prolonged campaigns by physicians and public health officials warning of the hazardous health effects of smoking, rates of cigarette smoking among American teenagers rose throughout the 1990s. The proportion of high school students identified as current smokers increased from 27.5 percent in 1991 to 34.8 percent in 1999 (CDC 2000). A more striking trend is that the incidence of initiation of first cigarette use by teenagers increased by 30 percent from 1988 to 1996, and first daily use increased by 50 percent over the same time period. It has been estimated that over 1.2 million teenagers became daily smokers in 1996 (CDC 1998).

The upward trend in smoking by adolescents is particularly troubling since the vast majority of adult smokers begin their habit during their teenage years (USDHHS 1994). As a result, recent public policy efforts to prevent smoking have concentrated on adolescents, and higher taxes and access restrictions have been identified as potential tools in reducing teenage smoking. Indeed, a number of empirical studies have examined the effectiveness of these policies in reducing cigarette consumption with mixed results. The results of these studies generally show that higher prices and decreased access to cigarettes will lower smoking by current smokers, but will have little impact on smoking initiation or experimentation.

A major factor contributing to smoking initiation and experimentation with cigarettes is the ability to borrow (Wolfson et al. 1997; Lucas and Lloyd 1999; Gratias et al. 1999; Emery et al. 1999). However, research to date examining the determinants of the demand for cigarettes by teenagers has ignored the impact of a lending/borrowing market on the smoking decisions of teenagers. This omission is despite the fact that 70 percent of students 
claim that the first cigarette they smoked had been given to them by another person, and 68.8 percent of students who report smoking in the past 30 days also report providing tobacco to another teen during the same period (Wolfson et al. 1997; Lucas and Lloyd 1999). Thus, understanding the lending/borrowing market is crucial when examining the factors influencing smoking decisions, particularly any decisions regarding teenage smoking initiation and experimentation. Further, as laws prohibiting sales of cigarettes to teens become more strongly enforced, the lending market can be expected to take on an even more important role as a source of cigarettes for teenagers.

Our paper begins with an examination of teenage smoking using a model of expected utility maximization that accounts for the presence of a lending/borrowing market for cigarettes. The model is particularly attractive in that it gives individuals a rationale for lending cigarettes within the neo-classical utility maximization framework. The basic idea behind the model is that an active lending/borrowing market acts as a safety net for smokers who do not have access to cigarettes. By becoming an established lender, a teen increases the likelihood of being able to borrow from other smokers if the need arises, thus insuring against a lack of cigarettes.

The theoretical model generates a host of predictions concerning smoking decisions based on the availability of cigarettes, properties of the lending/borrowing market, personal preferences, market prices, taxes, and other anti-smoking policies. First, it demonstrates the conditions under which an adolescent will primarily choose to "bum" cigarettes for consumption rather than purchase his own cigarettes. Second, once the decision to purchase cigarettes has been made, it shows how a smoker optimally allocates his cigarettes between lending 
and consumption. Regarding the purchasing decision, the model suggests that higher prices will induce some smokers to switch from purchasing cigarettes to primarily bumming them from others. In addition, those that continue to buy their cigarettes will continue to lend a constant amount, but will reduce the number of cigarettes purchased for self-consumption. Our model also shows that these price effects are reinforced by other anti-smoking policies that impact the chances that a teen is without his purchased cigarettes. Finally, it is shown that not only are the two types of policies important factors in discouraging teenage smoking, but that it is empirically crucial to control for one while estimating the impact of the other.

The theoretical predictions offer new insight into the lending/borrowing market utilized by teenagers. The remainder of the paper offers an empirical analysis of teenage smoking decisions based on the Youth Risk Behavior Surveys (YRBS). The main advantage of these data is that we are able to distinguish teens that tend to bum their cigarettes from those who buy their own, thus providing a finer partition (than existing studies which do not discern between the two types) of the effects of anti-smoking policies on teenage smokers. Our results also provide a better understanding of existing empirical results (see the literature review below). At the same time, the unique nature of the data generates numerous tests of our theoretical model, as well as estimates measuring the effectiveness of both price and non-price based anti-smoking policies.

Our empirical results are consistent with the predictions from the theoretical model. We establish that the probabilities of buying cigarettes and being a heavy smoker decrease with price, while the probabilities of bumming cigarettes and being a light smoker increase with price. Given the teenager smokes, the empirical results also confirm that consumption 
of cigarettes by buyers (bummers) is (is not) responsive to price changes. As with price, increased smoking restrictions in schools will impact the consumption of cigarettes by those who primarily buy, but have no impact on those who primarily bum.

The predictions from our theoretical model, taken together with the results from the empirical estimation, have strong implications for tax policy and other policies designed to deter teenage smoking. We present evidence that raising the price of cigarettes will have little to no impact on the consumption of cigarettes by teens who bum cigarettes and who smoke small quantities. However, this is not to say that tax policy will be ineffective in reducing teenage smoking. Not only will higher prices reduce the quantity smoked by heavy smokers, but as prices rise, more teens will attempt to bum cigarettes rather than purchase their own. Therefore, the pool of willing lenders shrinks while the number of bummers increases as prices rise with the result that more teenagers will compete for fewer cigarettes available for bumming.

\section{Previous Research}

The following is a review of studies that investigate adolescent smoking. In general, the consensus among price studies is that higher cigarette prices will lower the probability of participating in smoking and lower the frequency of smoking (conditional on being a smoker).

A common thread among these studies is the use of the Cragg (1971) two-part model to estimate these participation and frequency effects. ${ }^{1}$ One of the earliest studies by Lewit et al. (1981) estimates the price elasticity of demand for adolescents 12-17 years old. They find

\footnotetext{
${ }^{1}$ These estimates are then transformed into the price elasticties of participation and frequency.
} 
participation and frequency elasticities of -1.20 and -0.25 , respectively, indicating that youth smoking participation is fairly responsive to price. Using data from the Monitoring the Future (MTF) surveys, Chaloupka and Grossman (1996) estimate participation elasticities ranging from -0.38 to -0.92 , and frequency elasticities ranging from -0.47 to -0.78 . Similarly, Evans and Huang (1998) use the MTF surveys from 1977-92 and 1985-92 to estimate participation elasticities of -0.20 and -0.50 for the two time periods, respectively. A recent study by Gruber (2000) finds prices to be an important determinant of smoking participation and frequency among older teens (high school seniors) however, the price coefficients and resulting price elasticities are statistically insignificant when younger teens (9th - 11th graders) are considered.

Despite the negative price effects described in the previous paragraph, there is little evidence that price changes impact the decision to initiate or experiment with smoking. In fact, a number of recent studies have identified insignificant price effects in models of teenage smoking initiation and experimentation. Emery et al. (2001) explicitly examine a group of experimental smokers. They find that cigarette prices are not statistically significant determinants of the probability of being an experimental smoker as compared to a nonsmoker. DeCicca et al. (2002) also find that higher cigarette taxes have no statistically significant impact on smoking initiation between 8th and 12th grade, although they find that prices do have an impact on the level of smoking. Using duration analyses, Douglas and Hariharan (1994) and Douglas (1998) find that an increase in the price of cigarettes has no impact on the decision of teenagers to start smoking. Tauras et al. (2001) conclude that cigarette prices are very important determinants of adolescent smoking initiation in 
the sense that the transition to daily smoking becomes less likely. However, the transition to smoking any quantity of cigarettes results in negative but statistically insignificant price effects. In sum, the studies of initiation and experimental smoking provide little evidence that such behavior is responsive to price changes.

Much of the empirical literature investigating the impact of non-price based anti-smoking policies, such as clean indoor air laws, demonstrates that such restrictions have negative effects on teenage smoking at all levels of smoking. Chaloupka and Grossman (1996) conclude that strong restrictions on smoking in public places significantly reduce both the prevalence and average consumption of cigarette smoking by adolescents. In regards to smoking initiation, Tauras et al. (2001) find that laws restricting students from smoking in public schools will lower the probability of smoking any quantity of cigarettes, while having no impact on the transition to daily smoking. In a theoretical paper, Smetters and Gravelle (2001) investigate the degree to which smoking restrictions impact smoking participation. Their model suggests that moderate levels of enforcement will generate the highest levels of smoking participation, while low and high levels of enforcement are associated with the lowest levels of participation.

Wasserman et al. (1991) examine cigarette demand by teenagers, as well as adults. Using an index of restrictions on smoking along with price, they find statistically insignificant price effects for both age groups, although stricter restrictions on smoking do reduce the demand for cigarettes. Further, exclusion of the smoking restriction index in the adult sample results in statistically significant price elasticities that are similar to those found in other studies of adults. A similar exercise is not performed for the sample of adolescents, therefore it 
is unknown if the inclusion of the smoking restriction index influences the price effects for teenagers.

In summary, the current literature considers a variety of issues concerning teenage smoking including price and restriction responsiveness of demand by both regular smokers and initiators. Our paper extends this research by considering each of these factors in cohesive theoretical and empirical models; thereby, allowing for a better understanding of the determinants of teenage smoking, as well as reconciling a number of seemingly contradictory established findings.

\section{Theoretical model}

In this section we build on the previous research by developing a theoretical model that examines not only the traditional influences of prices and other anti-smoking policies, but also the impact of a lending/borrowing market on the expected utility maximization problem of a potential teen smoker. In our model, an individual receives positive, diminishing marginal utility from consumption of cigarettes $(c)$ and all other goods $(A)$. Along with choosing the number of cigarettes and all other goods to purchase, the individual must also decide how to allocate the number of cigarettes purchased between those consumed personally and those lent to others.

Since cigarettes are a consumption good, the contribution of cigarettes smoked $(c)$ to overall utility is obvious. Lending $(l)$ on the other hand is not a consumption good and the reason why a teen lends cigarettes is not completely apparent. It is possible that individuals derive utility from gift giving, although this motive seems inadequate given that cigarette 
lending is extremely prevalent among smokers and that the recipients of the gifts are often strangers. While gift giving may apply in some instances, our explanation for cigarette lending relies on a more self-interested motive. We treat lending as a means by which an individual can insure against a lack of cigarettes in the future. The need to insure against such instances may arise because a teen does not have the resources to purchase cigarettes, was unable to purchase cigarettes because of the enforcement of minimum purchase age laws, or purchased cigarettes that were later lost, stolen, or confiscated by parents or other authorities. We assume that a teen who has purchased cigarettes ends up without them with probability $1-q$.

The uncertainty as to whether or not a teen has his cigarettes provides the incentive to lend so long as current lending behavior is rewarded by an increased likelihood of being able to borrow in the future if the teen is without his cigarettes. That is, a teen is more likely to be recognized as a lender or run into someone to whom he has lent and thus be able to

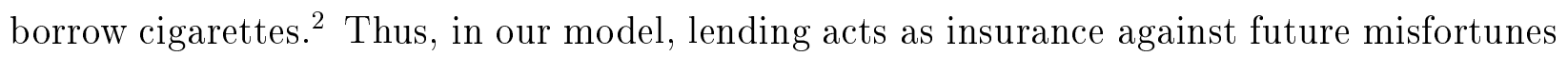
if lending begets lending.

Unfortunately, the lending market is complicated by the presence of perpetual "bumming" behavior. This behavior is primarily displayed by those who are in the initiation or experimental phases of smoking and free-ride on the lending market by continually borrowing cigarettes instead of buying their own. Because potential lenders do not know the past lending behavior of every borrower, they do not necessarily know whether a borrower is an active participant in the lending market who does not have cigarettes with him, or if he is

\footnotetext{
${ }^{2}$ This could be viewed in the exact opposite context as a constant borrower is more likely to run into someone that recognizes them as a non-lender and refuses to lend.
} 
a perpetual free-rider on the lending market. We distinguish between these two types of individuals by referring to the former as a borrower and the later as a bummer of cigarettes. The fact that these two types can not be perfectly distinguished carries the additional implication that if a teen has lent in the past, he is not guaranteed the ability to borrow in the future, it is only more likely that he will be able to borrow. Consequently, expected utility must be taken over all possible levels of borrowing $(x)$ according to some probability distribution, $\Phi$. We assume that $\Phi$ depends on the teen's lending level in the previous period $^{3}$ and is also potentially conditional on his income and the price of cigarettes (i.e. $\left.\Phi\left(x \mid l_{t-1}, P, Y\right)\right)$. Further, it is assumed that the returns to lending are marginally diminishing (i.e. $\left.d^{2} \Phi / d l_{t-1}^{2}<0\right)$. Finally, since those that do not lend (bummers) are sometimes able to borrow, $\Phi(x \mid 0, P, Y) \neq 0$.

It is important to notice that we allow for (but do not assume) possible dependence of the probability of being able to borrow on price and income. This allows for the following type of lending market phenomenon. Imagine a situation where the price rises and a teen continues to lend the same amount as before the price increase. Other lenders will notice that while the amount of lending has not changed, the cost to the individual has increased, and he should be thusly compensated via a higher probability of being able to borrow in the future. This case could be modeled by simply allowing the probability of being able to borrow to be conditional on expenditures on lent cigarettes rather than on lending and price separately. However, our assumption of conditionality $\left(\Phi\left(x \mid l_{t-1}, P, Y\right)\right)$ encompasses this and

\footnotetext{
${ }^{3}$ It is probably more realistic to let borrowing potential depend on an individual's entire history of lending. However, this greatly complicates the mathematics and we use previous period lending as a proxy without loss of generality.
} 
many other possibilities. Since a similar interpretation may also apply to income (someone with less wealth is seen as having incurred a greater cost) we allow for dependence on it as well. Before continuing, we stress that it is not assumed that the probability of being able to borrow depends on price and income, we simply allow for the possibility. The equilibrium from the model will indicate the impact of conditioning on price, thus generating predictions that can be tested using our data.

Since we are concerned with teenagers, we formulate their expected utility over the finite number of periods, $T$, that they will be active in the adolescent lending market. ${ }^{4}$ It follows that a teen with discount factor $\beta$ has an expected utility of

$$
\sum_{t=1}^{T} \beta^{t-1}\left\{q U\left(c_{t}, A_{t}\right)+(1-q) \int_{0}^{\bar{L}} U\left(x, A_{t}\right) \Phi^{\prime}\left(x \mid l_{t-1}, P, Y\right) d x\right\},
$$

where $l_{0}=0$ and $\bar{L}$ is the maximum number of cigarettes a teen can possibly borrow in a time period.

Empirical results concerning the lending market indicate that the utility maximized by a teenager is slightly less complicated than that given by Equation (1). The data presented in the next section show that when teenagers are able to borrow, the quantity obtained is small and tends to be fixed. On days that they smoke, 67 percent of borrowers smoke 1 cigarette or less. Thus, the distribution of cigarettes being lent is simplified (as is the mathematics) as follows. A teen can secure a fixed number of cigarettes $(\bar{L})$ with probability $\Phi\left(l_{t-1}, P, Y\right)$, or zero cigarettes with probability $1-\Phi\left(l_{t-1}, P, Y\right)$. As a result, a buyer of cigarettes faces the following three possible states of the world in each period.

\footnotetext{
${ }^{4}$ Analysis of the adult smoking market would differ in that it would be better modeled using an infinite time horizon.
} 
1. The adolescent buys cigarettes and maintains possession of them (i.e. there is no reliance on the lending/borrowing market).

2. The adolescent buys cigarettes, is without them, and secures $\bar{L}$ cigarettes from the lending/borrowing market.

3. The adolescent buys cigarettes, is without them, and comes up empty in the lending/borrowing market.

States 1, 2, and, 3 are governed by probability measures over the likelihood that the adolescent will be without his purchased cigarettes $(1-q)$ and that he will be able to borrow $(\Phi)$. State 1 occurs with probability $q$. State 2 arises with probability $(1-q) \Phi\left(l_{t-1}, P, Y\right)$ and state 3 happens with probability $(1-q)\left[1-\Phi\left(l_{t-1}, P, Y\right)\right]$. A teen who chooses not to buy cigarettes and depends entirely on the lending market sets $c_{t}, l_{t}=0$ and spends $Y$ on all other goods. Since this teen has not purchased cigarettes, he is able to bum with probability $\Phi\left(l_{t-1}, P, Y\right)$ or unable to bum with probability $1-\Phi\left(l_{t-1}, P, Y\right)$. It should be stressed that these "bumming" types are distinctly different than those who receive no utility from smoking and would not consume borrowed cigarettes even if they came across them. Refusal to smoke is interpreted as having no preference for cigarettes. Under the above simplifications, a teenager's general expected utility becomes

$$
\sum_{t=1}^{T} \beta^{t-1}\left\{q U\left(c_{t}, A_{t}\right)+(1-q)\left[\Phi\left(l_{t-1}, P, Y\right) U\left(\bar{L}, A_{t}\right)+\left(1-\Phi\left(l_{t-1}, P, Y\right)\right) U\left(0, A_{t}\right)\right]\right\} .
$$

If this maximization problem generates an interior solution the teen will purchase some amount of cigarettes for consumption and lending, $c_{t}, l_{t}>0$. If the problem produces a corner solution a teen with preference for cigarettes will not buy them (i.e., $c_{t}, l_{t}=0$ ), but 
will bum cigarettes when the opportunity arises. Whether an interior or corner solution results depends on the teenager's preference for cigarettes relative to all other goods and the parameters of the model such as price.

Before continuing, it is important to notice that although certain restrictions have been made in the model for reasons of tractability, this framework is easily generalized and our results can be applied to many other situations not directly encompassed by the model. Such applicable situations include cases where a teenager desires to purchase cigarettes, but is denied due to minimum purchase age laws and possibly forced to pay a fine. This, and a number of other anti-smoking laws, are manifested in the probability $q$. As such, interpretation of our theoretical results pertaining to changes in the $q$ parameter can be taken quite generally.

\subsection{A Model Without the Possibility of Substitution Effects}

We begin our analysis with the simple case where utility depends solely on cigarette consumption, $U\left(c_{t}\right)$, thereby ignoring substitution effects with all other goods. ${ }^{5}$ The purpose of this simplification is threefold. First, it allows us to focus on how cigarette purchases are split between consumption and lending. Second, this version generates analytically tractable comparative statics. As shown below, the inclusion of all other goods results in an analytically intractable problem, thus necessitating the use of numerical methods. Finally, it provides an initial examination of the properties of $\Phi\left(l_{t-1}, P, Y\right)$ that will aid in selecting a functional form when we turn to the more elaborate model with substitution effects in the next section.

\footnotetext{
${ }^{5}$ Eliminating substitution effects is tantamount to assuming that there is no bumming behavior.
} 
In this setting, the teenager optimizes

$$
\sum_{t=1}^{T} \beta^{t-1}\left\{q U\left(c_{t}\right)+(1-q)\left[\Phi\left(l_{t-1}, P, Y\right) U(\bar{L})+\left(1-\Phi\left(l_{t-1}, P, Y\right)\right) U(0)\right]\right\}
$$

subject to the budget constraints $Y=P c_{t}+P l_{t}$ and non-negativity constraints on $c_{t}$ and $l_{t}$. Letting $\lambda_{t}$ denote the Lagrangian multiplier on the period $t$ budget constraint, the first order conditions reduce to

$$
\begin{gathered}
(1-q) \beta \Phi_{1}\left(l_{t}, P, Y\right)[U(\bar{L})-U(0)]-\lambda_{t} P=0, \quad \forall t=1, \ldots, T-1, \\
q U^{\prime}\left(c_{t}\right)-\lambda_{t} P=0, \quad \forall t=1, \ldots, T, \\
Y-P c_{t}-P l_{t}=0, \quad \forall t=1, \ldots, T .
\end{gathered}
$$

Notice that the first order condition for lending only applies to the first $T-1$ periods. The reason is that in period $T-1$, the teenager knows that he will be leaving this market the next period and will not be around to reap the insurance benefits. Thus, the lending decision is degenerate in the final period and $l_{T}=0$.

The second order condition for a maximum can be written as

$$
q U^{\prime \prime}\left(c_{t}\right)+(1-q) \beta \Phi_{11}\left(l_{t}, P, Y\right)[U(\bar{L})-U(0)]<0
$$

which is clearly satisfied under our assumptions of increasing utility and diminishing marginal utility and returns on lending. Since Equations (4), (5), and (6) include only period $t$ variables, the comparative statics are straightforward. This will not be the case when all other goods are added as there is a time interaction in the equations (i.e. period $t$ and $t+1$ variables are in the same equation). 


\subsubsection{Price Effects}

The effects of price changes on cigarette consumption and lending are seen in the following comparative statics:

$$
\begin{aligned}
\frac{d c_{t}}{d P}= & \frac{(1-q) \beta[U(\bar{L})-U(0)] \Phi_{12}\left(l_{t}, P, Y\right)}{q U^{\prime \prime}\left(c_{t}\right)+(1-q) \beta \Phi_{11}\left(l_{t}, P, Y\right)[U(\bar{L})-U(0)]} \\
& -\frac{(1-q) \beta[U(\bar{L})-U(0)] \Phi_{11}\left(l_{t}, P, Y\right) \frac{Y}{P^{2}}}{q U^{\prime \prime}\left(c_{t}\right)+(1-q) \beta \Phi_{11}\left(l_{t}, P, Y\right)[U(\bar{L})-U(0)]}, \\
\frac{d l_{t}}{d P}= & \frac{-q U^{\prime \prime}\left(c_{t}\right) \frac{Y}{P^{2}}[U(\bar{L})-U(0)]}{q U^{\prime \prime}\left(c_{t}\right)+(1-q) \beta \Phi_{11}\left(l_{t}, P, Y\right)[U(\bar{L})-U(0)]} \\
& -\frac{(1-q) \beta \Phi_{12}\left(l_{t}, P, Y\right)[U(\bar{L})-U(0)]}{q U^{\prime \prime}\left(c_{t}\right)+(1-q) \beta \Phi_{11}\left(l_{t}, P, Y\right)[U(\bar{L})-U(0)]} .
\end{aligned}
$$

The denominators of both comparative statics are negative by the second order condition. Negative price effects will result on both variables if $\Phi_{12}\left(l_{t}, P, Y\right)$ is zero. If, however, the probability of borrowing is conditional on price, this will skew the relative magnitudes of the numerators of both comparative statics since the $\Phi_{12}\left(l_{t}, P, Y\right)$ term adds to (subtracts from) consumption responsiveness to price and subtracts from (adds to) lending responsiveness to price when $\Phi_{12}\left(l_{t}, P, Y\right)>0(<0)$.

\subsubsection{Restriction Effects}

Clean indoor air laws such as bans on smoking in schools can have measurable effects on teenage cigarette consumption. Smetters and Gravelle (2001) show that such policies may possess a non-monotonic relationship where increasing the degree of enforcement leads to 
more cigarette lending when policy is somewhat lax ( $q$ is large in our terms), but eventually leads to decreased lending as policy becomes stringent ( $q$ is small). They provide an explanation for this relationship using a utility model where smoking with a peer decreases the probability that a teen will be caught smoking, thus providing an incentive to lend. While our model does not assume that the behavior of others affects utility in this way, when $q$ is viewed as a measure of the relative harshness of this policy, the following comparative statics suggest a similar finding:

$$
\begin{aligned}
& \frac{d c_{t}}{d q}=\frac{\beta \Phi_{1}\left(l_{t}, P, Y\right)[U(\bar{L})-U(0)]-U^{\prime}\left(c_{t}\right)}{q U^{\prime \prime}\left(c_{t}\right)+(1-q) \beta \Phi_{11}\left(l_{t}, P, Y\right)[U(\bar{L})-U(0)]}, \\
& \frac{d l_{t}}{d q}=\frac{U^{\prime}\left(c_{t}\right)-\beta \Phi_{1}\left(l_{t}, P, Y\right)[U(\bar{L})-U(0)]}{q U^{\prime \prime}\left(c_{t}\right)+(1-q) \beta \Phi_{11}\left(l_{t}, P, Y\right)[U(\bar{L})-U(0)]} .
\end{aligned}
$$

It is easily seen from the two derivatives that as $q$ changes, what is added or taken away from consumption is replaced by lending. However, the direction of the change depends on the original magnitude of $q$. This is seen by comparing the numerators with the equation that results combining Equations (4) and (5). Since the numerators of Equations (10) and (11) are identical to the resulting equation, with the exception of the $q$ and $(1-q)$ terms, the sign of Equation (10) will be negative (positive) when $q$ is less (greater) than 0.5 and Equation (11) will be positive (negative) when $q$ is less (greater) than 0.5 . This result is consistent with the non-monotonic relationship between smoking participation and anti-smoking policy enforcement empirically documented by social psychologists (see Smetters and Gravelle 2001 for a review of that literature). 


\subsection{A Model with Substitution Effects}

We now turn to the case where utility depends not only on cigarette consumption, but also on consumption of all other goods. The teenager's problem is now to maximize Equation (2) subject to the budget constraints $Y=A_{t}+P c_{t}+P l_{t}$, and a non-negativity constraint on each variable. The budget constraint normalizes the price of all other goods to one. Letting $\lambda_{t}$ denote the Lagrangian multiplier on the period $t$ income constraint, the teenager's maximization problem yields the following first order conditions:

$$
\begin{aligned}
(1-q)\left[\Phi\left(l_{t-1}, P, Y\right) U_{2}\left(\bar{L}, A_{t}\right)+\left(1-\Phi\left(l_{t-1}, P, Y\right)\right) U_{2}\left(0, A_{t}\right)\right] & \\
+q U_{2}\left(c_{t}, A_{t}\right)-\lambda_{t} & =0 \\
q U_{1}\left(c_{t}, A_{t}\right)-\lambda_{t} P & =0, \\
(1-q) \beta \Phi_{1}\left(l_{t}, P, Y\right)\left[U\left(\bar{L}, A_{t+1}\right)-U\left(0, A_{t+1}\right)\right]-\lambda_{t} P & =0, \\
Y-A_{t}-P c_{t}-P l_{t} & =0 .
\end{aligned}
$$

Equations (12), (13), and (15) are defined for $t=1, \ldots T$, while Equation (14) is only defined for $t=1, \ldots, T-1$ since the degeneracy of the lending choice in period $T$ discussed above applies here as well. The problem is then to solve for the $4 T$ variables $\left(l_{1}, \ldots, l_{T}, c_{1}, \ldots, c_{T}, A_{1}, \ldots, A_{T}, \lambda_{1}, \ldots, \lambda_{T}\right)$ using the $4 T-1$ first order equations and the degeneracy condition $l_{T}=0$. Although difficult to check using the Hessian, the assumptions

of diminishing marginal utility and returns to lending assure that the objective function is globally strictly concave. Thus, compactness of the constraint set assures a unique solution (not necessarily interior). Unfortunately, the time interaction in the first order conditions 
(the presence of period $t$ and $t+1$ variables in the same equation) fails to produce an analytic solution. Hence, we examine the nature of the solution and comparative statics using numerical methods.

\subsubsection{Numerical Methods}

We begin by specifying the well known Cobb-Douglas utility function, $U=(1+A)^{\alpha}(1+c)^{\gamma}$. This form of utility has two desirable properties. First, it allows for the presence of smokers $(\gamma>0)$ and non-smokers $(\gamma=0)$ alike. Second, it admits both interior and corner solutions for various taste parameters. The numerical calculations below were performed using MATLABC for Cobb-Douglas parameters $\alpha=0.3, \gamma=0.3 .{ }^{6}$ We specify that $\Phi\left(l_{t-1}, P, Y\right)$ takes on the functional form $0.5+0.5 \sqrt{P l_{t-1} / Y} \cdot{ }^{7}$ This allows $\Phi$ to be conditional on $P$ and $Y$ and ensures an upper bound of one on the probability when the teenager spends every available dollar, $Y / P$, on cigarettes earmarked for lending. This form is concave in $l$ as lending is assumed to generate diminishing marginal returns. Also, the term $\Phi_{12}\left(l_{t}, P, Y\right)$ that was of consequence in our discussion of elasticity above is positive. Other parameters are set at $Y=100, \beta=0.9, q=0.5$, and $\bar{L}=10$. Finally, the numerical examples were generated for the case where $T=3$, without loss of generality. ${ }^{8}$

Figure 1 identifies the range of taste parameters with preference for cigarettes $(\gamma)$ and

\footnotetext{
${ }^{6}$ These randomly selected parameters, as well as a wide array of other parameter values, generate interior solutions. If $\alpha$ and $\gamma$ are too far apart, corner solutions result. This issue is examined in detail below.

${ }^{7}$ We ran all numerical examples on a probability function that was not conditional on price and found quite different results. Not suprisingly, these results did not match well with empirical findings; thus, providing additional support for the assertion that borrowing probability is conditional on price.

${ }^{8} \mathrm{~A}$ minimum of three periods is necessary to analyze the model for the following reason. If there where only two periods, a first period lender would be recognized as a lender in period two which would also convey that they would be out of the market in the next period. Hence, no one would lend to them in the second period and thus, they would have no reason to lend in the first period.
} 
preference for all other goods $(\alpha)$ on the horizontal and vertical axes respectively. The various regions of this figure have significant empirical and policy implications. The white region represents types that purchase and lend cigarettes. The light grey region identifies types that do not buy cigarettes but do attempt to obtain them in the lending market. Teenagers that do not smoke in any instance are located on the vertical axis where $\gamma=0$.

Figure 1 highlights the fact that those with a strong preference for cigarettes relative to all other goods tend to buy their cigarettes. Those with a strong preference for all other goods relative to cigarettes will smoke cigarettes, but will tend to be bummers that only consume borrowed cigarettes. The black region, which represented buyers before the price change, depicts the effect of a price increase as these types now choose to bum their cigarettes. That is, as the price of cigarettes increases, the upper region grows to include more types, indicating that fewer types buy their cigarettes and more begin to bum. It will be shown below that bummers tend to consume far fewer cigarettes than buyers, hence; the model predicts that tax policy can have a substantial impact on the number of cigarettes smoked by teens. Further, this implies that tax policy may decrease the probability of transition from experimental to regular smoking. Finally, the fact that there are fewer buyers indicates that there will be fewer cigarettes available for borrowing and thus, it will be harder for new smokers to find cigarettes with which to experiment. This last prediction corresponds to the Forster and Jones (1999) finding that higher taxes postpone the age of onset of smoking initiation.

Figure 2 illustrates how a teen adjusts his lending behavior $\left(l_{1}\right.$ and $l_{2}$, recall $l_{3}$ is equal to zero) as the price increases. Clearly, lending decreases as the price of cigarettes increases, 
but the function becomes very flat, in line with our empirical results that will illustrate lending is relatively unresponsive to price changes. Figure 3 shows how this type of consumer adjusts cigarette consumption $\left(c_{1}, c_{2}\right.$, and $\left.c_{3}\right)$ in response to price changes. As with lending, the curve becomes relatively flat, corresponding to the common empirical finding that cigarette consumption is relatively unresponsive to price changes. Clearly, we are dealing with two quantities that are relatively non-responsive to price changes. Figure 4 shows that consumption is relatively more responsive than lending. ${ }^{9}$

Figure 5 compares the price elasticities of consumption and lending. The model predicts that as prices rise, consumption elasticity measures increase in absolute value, but the price elasticity of lending stays somewhat constant (and inelastic). This implies that price increases will have a larger effect on consumption than on the amount of cigarettes lent out by purchasers. This is consistent with established empirical findings that price affects the quantity of cigarettes consumed by regular smokers and has very little effect on the quantity of cigarettes consumed by initiators and experimenters who rely on the lending of others.

Figure 6 illustrates the impact of the restriction parameter $(q)$ on consumption and lending. The intuitive relationship is seen as lower values of $q$ generate lending levels that are much higher than consumption. This is the result of two effects. First, the fact that the teen is more likely to be without his cigarettes encourages him to lend them rather than to save them for consumption. Second, since he is also likely to be without cigarettes in the following period, he tends to lend more in the current period so that he is more likely to be able to borrow in the next period. As $q$ increases, the incentives become reversed. That

\footnotetext{
${ }^{9}$ Although the values are slightly different, the picture for period two is qualitatively the same.
} 
is, since it is less likely that he will be without his cigarettes, the teen is apt to keep his cigarettes for personal consumption and since he is more likely to have his cigarettes next period, the incentive to lend is lessened.

Figure 7 illustrates the changes in the price elasticity of consumption and lending that result from a change in $q$. Recall that low values of $q$ are consistent with a high probability of being without ones cigarettes. Figure 7 demonstrates that as $q$ rises, the price elasticity of consumption becomes very elastic. Decreases in $q$ will force the price elasticity of consumption to be more inelastic. Meanwhile, changes in $q$ have relatively little effect on the price elasticity of lending. The price elasticity of lending remains inelastic for all values of $q$, however, for high values of $q$ (low probability of being without ones cigarettes) the price elasticity of lending is much more inelastic than the price elasticity of consumption. This has significant empirical implications as it highlights the importance of controlling for both tax and non-price based policies simultaneously when estimating their effects on smoking.

Figure 8 shows how the teenager adjusts consumption of all other goods as cigarette prices rise. This aspect of the model is lost when utility was assumed to be independent of the consumption of all other goods (i.e. Section 3.1). The disparity in the Period 1 and 2 , and 3 curves arises from the degeneracy condition on period three lending. The positive slope of the curve simply indicates that as cigarettes become more expensive, the teenager tends to substitute away from cigarettes. Recall that this substitution subtracts mainly from cigarette consumption and not lending.

The theoretical models with and without substitution possibilities generate testable predictions that we investigate empirically in the following section. The results from the model 
without substitution effects demonstrate that if $\Phi$ is conditional on $P$ then consumption will be more responsive to price changes than lending. This result is upheld in the model with substitution effects. In addition, the model without substitution effects describes a non-monotonic relationship between the level of smoking restrictiveness and the amount of lending. Therefore, for higher levels of enforcement we predict lower levels of lending. Another interesting finding is that the price elasticity of lending is less responsive to changes in $q$ than is the price elasticity of consumption.

\section{Data and Empirical Estimation}

This section empirically examines the fundamental differences between teens that primarily buy and those that primarily bum cigarettes; thus, allowing for an assessment of the impacts of various anti-smoking policies on each. We begin by discussing the data and selection of covariates and proceed in manner similar to the theoretical section, allowing the reader to compare the corresponding empirical and theoretical findings more easily. In fact, it is shown that our theoretical and empirical results are consistent, indicating the accuracy of the theoretical model.

\subsection{Data}

The ideal data set with which to test our model would contain a panel of adolescents across time, and would have information on the number of cigarettes bought, consumed, lent, and borrowed in each time period. In the absence of such data, we use the 1995, 1997, and 1999 Youth Risk Behavior Surveys (YRBS), consisting of nationally representative samples of high 
school students in grades 9-12, and which provide information on cigarette consumption, socio-economic characteristics, and most importantly, buying and bumming behavior.

Buyers and bummers are identified using the respondents' answer to the question, "During the past 30 days, how did you usually get your own cigarettes?" Only one response is allowed. Buyers are identified as teenagers who chose one of the following responses: "I bought them in a store such as a convenience store, supermarket, or gas station"; "I bought them from a vending machine"; or "I gave someone else money to buy them for me". Bummers are identified as people who said they usually borrowed cigarettes from someone else. ${ }^{10}$ Responses to this question point to the importance of borrowing in analyzing teen smoking as over one third (36 percent) indicate borrowing as their primary means of obtaining cigarettes.

Clearly, factors such as cigarette prices and taxes, smoking restrictions, socio-economic characteristics, and individual preferences are key in determining whether a teen becomes a buyer or bummer and subsequent consumption patterns. These variables match well with the parameters of the theoretical model $(P, q, Y, \alpha, \beta, \gamma)$ and are included in our estimations as follows:

1. Cigarette Consumption $(c)$ : We use two alternative measures of the amount of cigarettes consumed by smokers. The first is the number of days on which the YRBS respondent smoked in the last 30 days. The possible responses include the following categories: 0 days, 1 or 2 days, 3 to 5 days, 6 to 9 days, 10 to 19 days, 20 to 29 days, all 30 days.

\footnotetext{
${ }^{10}$ There are two other possible answers to the question: I stole them (4 percent of the sample); and I got them some other way (9 percent). For simplicity, people giving these responses are omitted from the analysis, although models were tested that include these respondents as bummers and the empirical results do not change.
} 
Each category is represented by the midpoint of its range. Those reporting smoking on zero days are treated as non-smokers. The second measure of smoking considered is the number of cigarettes smoked on the days that the respondent smokes. The possible responses are zero, less than per 1 day, 1 per day, 2 to 5 per day, 6 to 10 per day, 11 to 20 per day and more than 20 per day. Again the midpoints of the ranges are used.

2. Cigarette Prices and Taxes $(P)$ : The price parameter in the model reflects the total outlay a buyer of cigarettes must make. As alternative measures of this, we use both real cigarette price (inclusive of taxes) and the state-level excise tax on cigarettes. Both are obtained from the Tobacco Council's Tax Burden on Tobacco. ${ }^{11}$

3. Non-price/Anti-smoking Policies $(q)$ : The modelling parameter $q$ is clearly correlated with legislation restricting teenage smoking. Such measures include clean indoor air laws that restrict the types of public places in which a teen can legally smoke. These laws vary by state and can be grouped into categories ranging from no restrictions to total prohibition. As such, four indicators of bans are used. The omitted reference category represents those states that have enacted no laws governing smoking in schools. Ban 1, the least restrictive, requires some form of a restriction on smoking that does not require a separately ventilated area, nor bans smoking entirely. Ban 2 requires either an enclosed, separated ventilated area or else smoking must be banned entirely.

\footnotetext{
${ }^{11}$ Price is used to provide estimates that are directly comparable to existing studies. However, prices may be endogenous if tobacco companies engage in state specific pricing (Gruber 2000). Taxes are less subject to this form of endogeneity. It has been argued that cigarette prices and taxes may also be endogenous if the respondent's smoking habits are reflective of the state-sentiment towards smoking which may influence the tax rate. An attempt is made to account for the possible endogeneity of prices and taxes by including dummies for the region of the country in which the teenager lives in all models. State dummies were tested but are not used because these variables are highly collinear with cigarette taxes. A regression of taxes on state dummies yields a $R^{2}$ of 0.86 .
} 
Finally, Ban 3 is a total prohibition on smoking in school. These data come from the ImpacTeen Project.

4. Socioeconomic and Demographic Characteristics (Y): YRBS data concerning these characteristics are very limited in that only age, class year, gender, and race are available in all years of the data. Class year is not included in the regressions because it is highly collinear with age. However, since all students of the same age are not in the same grade level, two variables are created that indicate whether or not the respondent's age is greater than that of the majority of the class, and whether or not the respondent's age is less than that of the majority of the class. The former will help identify students who have repeated grades while the later will identify students who have skipped grades. Next, although income is not directly observable, we include real income per capita and the unemployment rate in the respondent's home state as proxies for the income and employment opportunities available to teenagers. These data are from the Bureau of Economic Analysis and Bureau of Labor Statistics.

5. Tastes and Preferences $(\alpha, \beta, \gamma)$ : Several additional measures related to the utility parameters and time preference from the theoretical model help control for the respondent's personality, propensity towards risk, and individual preferences. The first reports how often the YRBS respondent wears a seat belt when he is a passenger in a car, and the second is the number of sports teams run by either the school or an outside organization on which the respondent plays. These variables may be endogenous in that they may be determined by the same unmeasured factors that predict smoking. So long as they are not correlated with anti-smoking policies, their inclusion 
will not bias the policy coefficients. Culture and religious affiliation may also affect attitudes/preferences for cigarettes. Thus, all estimations include the percentage of the respondent's state that are Mormon, Protestants, Southern Baptist, and Catholic. Data on religious affiliation come from Bradley et al. (1992). Lastly, dummy variables representing the region of the country in which the respondent lives are included to capture some of the unobserved area-level sentiment towards smoking. ${ }^{12}$

\subsection{Estimation and Empirical Results}

We begin our empirical analysis by pointing out the strong correlation between buying (bumming) cigarettes, heavy (light) consumption, and regular (experimental) smoking. On average, bummers tend to smoke less than buyers in two respects. First, bummers smoke 5.81 days per month whereas buyers smoke 19.88 days per month. Second, on days that they smoke, bummers consume 1.82 cigarettes whereas buyers smoke 6.04. Table 1 indicates that bummers are much more likely than buyers to be light smokers as 73 percent of bummers smoke on five or less days per month whereas only 20 percent of buyers report smoking on five or less days per month. In addition, on days that they smoke, 67 percent of bummers smoke one or less cigarettes, while only 18 percent of buyers smoke one or less cigarettes. Table 2 provides evidence that those who bum cigarettes have more recently initiated smoking. Almost a quarter of bummers smoked their first cigarette less than two years before the survey while only 11 percent of buyers started as recently. In fact, nearly half of the buyers

\footnotetext{
${ }^{12}$ Where applicable, observations are deleted from the sample if the quantity of smoking or manner in which the respondent obtains cigarettes are unknown. Also deleted are observations with missing values on the other individual characteristics. For age, gender, race, seat belt use, and sports teams, this accounts for less than 1 percent of the sample.
} 
(44 percent) have been smoking 5 or more years, while only 25 percent of bummers have been smoking for that long.

As previously discussed, Figure 1 displays the theoretical prediction that price increases will reduce the number of teens who buy their cigarettes at the expense of an increased number of teens bumming cigarettes. The above statistics indicate that if the model is correct, price increases should greatly reduce the number of cigarettes consumed by all teens since buyers tend to be heavier smokers than bummers. In order to substantiate the prediction encompassed by Figure 1, we group respondents into the three pertinent categories (non-smokers, bummers, buyers) and examine the impact of each variable on the probability of being in a given category.

Formally, we estimate the marginal effects of the probability function $\pi(P, q, Y, \alpha, \gamma, \beta)$. Initially, multinomial logits are used to examine the determinants of the probability of being a non-smoker, bummer, or buyer. Next, the sample is restricted to include only current smokers in order to examine the behavior of teens with preference for cigarettes. In this case logits are used to examine the impact of prices, taxes, and our other variables on the probability of being a buyer versus a bummer. ${ }^{13}$

The top half of Table 3 provides the marginal impacts of price changes on whether a teen is a non-smoker, bummer, or buyer. The results show that changes in the probability of participation brought about by changes in prices are not statistically significant. While higher prices may not induce a shift between smoking and non-smoking amongst teens,

\footnotetext{
${ }^{13}$ All empirical models include the complete set of independent variables described above. For brevity, the results for these other variables are not shown in Tables 3 and 4. In addition, all empirical models were tested using standard errors adjusted according to Huber (1967) which account for correlation in the error terms among individuals living in the same state. Results are not shown, because while the Huber-adjusted standard errors increase, statistical significance is unaffected.
} 
there is an effect on the composition of teens that buy cigarettes relative to those that bum cigarettes. The second half of Table 3 provides the statistically significant, negative marginal effect on the probability of being a buyer. That is, as prices increase, the probability of a teen buying his cigarettes decreases and manifests itself as an increase in the probability that he will bum cigarettes. This exactly matches the predictions of the model housed in Figure 1.

The intuition behind the above finding is that as cigarettes become more expensive, a teen has an incentive to substitute away from the purchased cigarettes towards other goods. As a result, he is more likely to become a bummer who relies on the lending market for cigarettes. Although not testable because of the lack of time series data, we conjecture that over time, some current buyers would shift to bumming behavior if prices increased. Finally, since bummers tend to consume fewer cigarettes, we expect that the shift from buyer to bummer will cause a reduction in the total number of cigarettes consumed by teens. This is the next topic explored.

Table 4 shows the impact of prices on the probabilities of different levels of smoking. Ideally, we would like to examine a teen's transition across levels of smoking as prices change over time. Once again, this is not possible with cross-sectional data. Rather, we examine the probabilities of consuming different levels of cigarettes at a given point in time. As in Table 3, we use two different samples of adolescents: the full sample of both smokers and nonsmokers, and the sample of only current smokers. Ordered logits are used to estimate these probabilities using our two alternative measures of consumption: (1) number of cigarettes consumed on days smoked and (2) number of days smoked. 
For the sample of current smokers, both measures of consumption in Table 4 result in statistically significant price and tax coefficients that produce marginal effects in line with our intuition and conjectures. Results for the full sample yield statistically insignificant price and tax coefficients. For smokers, focusing first on the number of cigarettes smoked on days smoked, raising the price or tax on cigarettes will lower the probabilities of smoking 2 to 5 cigarettes per day and 6 or more per day, and will raise the probability of smoking less than 2 per day. Similarly, higher prices and taxes will decrease the probability of smoking 10 days or more a month and will raise the probability of smoking less than 10 days a month. Together, these results indicate that higher cigarette prices and taxes will raise the probability that an adolescent will be a light smoker and will lower the probability of being a heavy smoker.

In regards to bans on smoking in schools, the top half of Table 3 confirms that certain types of bans will impact smoking status. For example, in the full sample, the requirement of a separate smoking area (Ban 2) and full prohibition (Ban 3) will lower the probabilities of being a buyer and will raise the probability of being a non-smoker. For current smokers, bans do not have a statistically significant impact on the probability of being a buyer versus bummer. In Table 4, the ban on smoking in schools generating the largest impact on cigarette consumption is the moderate level restriction requiring a separate smoking area (Ban 2). When considering either measure of consumption for the full sample, imposing this ban will raise the probability of smoking zero cigarettes and lower the probability of smoking any positive quantities. A total prohibition of smoking (Ban 3) has a similar effect on both measures of cigarette consumption, although the magnitudes of the marginal effects are smaller. For the sample of current smokers, the signs of the marginal effects show that 
all three types of bans will lower the probabilities of smoking large quantities (i.e. 2 to 5 cigarettes per day and 6 or more per day) and will raise the probability of smoking smaller quantities. Only the coefficients on school Bans 1 and 2 are statistically significant. Similar statements apply when considering the number of days smoked as the measure of cigarette consumption in Table 4. The fact that the intermediate ban has the largest effect corresponds to the non-monotonic (u-shaped) relation between non-price based policies and consumption found in Equation (10) above and by Smetters and Gravelle (2001).

The results in Tables 3 and 4 strongly suggest that increased prices and certain restrictions on smoking lower the number of cigarettes smoked by teens. We now examine how price changes and bans affect those that choose to smoke cigarettes. This provides insight into how price and bans affect the allocation of purchased cigarettes between those self-consumed and those lent, as well as providing numerous tests of our theoretical model.

The theoretical model defines the relation between a cigarette buyer's demand for cigarettes to be lent and those to be self-consumed. Equations (12)-(15) imply the following implicit and explicit relationships between these choices and our covariates,

$$
\begin{aligned}
c_{t} & =f\left(P, q, Y, l_{t-1}, \alpha, \gamma, \beta\right) \\
l_{t} & =g\left(P, q, Y, l_{t-1}, \alpha, \gamma, \beta\right) .
\end{aligned}
$$

Estimating Equations (16) and (17) is complicated by two factors. First, while we observe buyer consumption patterns, we do not observe their lending patterns in the data. Therefore, while we can directly estimate Equation (16), we must indirectly estimate Equation (17). Indirect estimation of Equation (17) is accomplished by noticing that bummer consumption 
provides an indirect measurement of lending since what is borrowed by one person must have been lent by another person. Hence, our empirical objects of interest are buyer and bummer consumption (see $\widetilde{c}_{t}$ and $\widetilde{b}_{t}$ below). Second, we do not have observations of single individuals across time. Thus, past period lending $\left(l_{t-1}\right)$ is not observed. However, since it is likely that current bummers were either bummers in the past or had not yet begun to smoke, it is probable that their past lending level was zero. In any case, as long as past lending is not correlated with current price and smoking restrictions, there will be no omitted variable bias by excluding a measure of past lending for either buyers or bummers. Hence, our task reduces to estimating the following equations:

$$
\begin{aligned}
& \widetilde{c}_{t}=f(P, q, Y, \alpha, \gamma, \beta) \\
& \widetilde{b}_{t}=g(P, q, Y, \alpha, \gamma, \beta) .
\end{aligned}
$$

Separate OLS estimates are obtained using Equations (18) and (19) and the two alternative measures of cigarette consumption. Estimates based on the number of cigarettes consumed on days the respondent smoked are found in Table 5. Estimates based on the number of days on which cigarettes are consumed are found in Table 6 . In other words, the estimates in Tables 5 and 6 show price effects for frequency conditional on being a smoker. ${ }^{14}$ In order to provide a base line estimate, the models are estimated first for the whole sample of smokers without regard to buying status, and are then estimated separately for buyers and bummers. ${ }^{15}$

\footnotetext{
${ }^{14}$ See Gruber (2000) for estimates of participation and frequency conditional on smoking without regard to buying status in the YRBS.

${ }^{15}$ The former regression is clearly not needed since the latter regressions can be used to test this restricted case. However, we offer the regression on the entire pool of smokers for comparisons to existing results that
} 
The results in Table 5 show that higher prices and taxes will lower the number of cigarettes smoked by all smokers and buyers but that consumption by bummers is not responsive to price changes. The negative price effect for all smokers appears to be due to the fact that buyers are a more substantial fraction of the market and smoke more than bummers. The frequency price elasticity for buyers is -0.282 and is in the range of frequency price elasticities found in other studies. Recall that the theoretical model from Section 3.1 predicts that cigarettes consumption by buyers will be more price responsive than lending due to the wedge $\left(\Phi_{12}\left(l_{t}, P, Y\right)>0\right)$ brought about by existence of the probability of being able to borrow. Thus, Table 5 provides evidence in favor of the model.

As with the number of cigarettes, Table 6 shows that higher prices and taxes will reduce the number of days smoked by all respondents and by those who buy their cigarettes. Table 5 shows that the number of cigarettes smoked by bummers on days that they smoked is not responsive to price changes; however, Table 6 shows the number of days on which a bummer smokes is responsive to price and tax changes. The frequency price elasticities for buyers and bummers are -0.28 and -0.475 , respectively. The discrepancy in the frequency price elasticities for bummers using the two different measures of consumption can be explained within the framework of the theoretical model. Recall from the model that cigarette consumption for bummers is governed by the probability $(\Phi)$ that a positive quantity of cigarettes will be obtained from the lending market, and the number of cigarettes that can be obtained given that cigarettes are lent $(\bar{L})$. For bummers, the number of days smoked can be viewed as corresponding to $\Phi$, and the number of cigarettes smoked on days that the bummer smokes

can not disect smokers into buyers and bummers. 
can be viewed as corresponding to $\bar{L}$. The price responsiveness of number of days is in line with the assumption that the probability of being able to borrow $(\Phi)$ is conditional on price, and the non-responsive price finding on the number of cigarettes smoked is in line with the non-stochastic assumption on $\bar{L}$.

Turning to the impact of smoking bans on consumption, Table 5 shows that certain types of bans on smoking in school will decrease the consumption of cigarettes by teens who buy their cigarettes, while none of the bans has a significant impact on the number of cigarettes consumed by bummers. Requiring an enclosed, separated ventilated area (Ban 2) has the largest impact on reducing smoking relative to no ban. A requirement of some form of restriction (Ban 1) will also decrease the consumption of buyers, but the magnitude is less than that of the ventilated area restriction. A full prohibition on smoking in schools (Ban 3) has a negative, but statistically insignificant impact on smoking. Again, these results are consistent with the findings of Smetters and Gravelle (2001). The results of the impact of smoking bans in schools in Table 6 are similar to those in Table 5.

\section{Discussion}

The empirical results examining the decisions of smokers confirm our prediction from the theoretical model that the cigarette consumption by those who buy their cigarettes can be lowered by increasing taxes. The impact of higher taxes on the consumption of cigarettes by bummers is not as clear. While the number of days that a bummer smokes is responsive to price and tax changes, the number of cigarettes smoked on those days is not. Additionally, higher prices and taxes actually increase the probability that a teen is a bummer of cigarettes 
(as opposed to being a buyer), as the theoretical model predicts.

Not only do our empirical results help confirm the accuracy of our theoretical model, they help reconcile seemingly contradictory findings concerning teenage consumption elasticities found in the current literature. Studies of regular smokers generally find that an increase in cigarette prices tends to reduce consumption. However, studies focusing on initiators and experimenters tend to find no price effects. Couched in terms of our model, these findings are perfectly compatible as the determinants of smoking by the two different groups are vastly different.

Empirically, we have shown a correlation between experimental smoking, bumming, and light consumption, as well as a similar correlation between regular smoking, buying, and heavy consumption. As prices rise, more smokers will be encouraged to try to bum rather than buy cigarettes with the result that any cross-sectional study examining light smoking can find an increase in light smoking concurrent with price increases. While we have shown that the ability to borrow varies with price, once a teen can successfully borrow, the quantity of these borrowed cigarettes consumed is not responsive to price.

We have demonstrated that higher cigarette prices may affect a teen's decision to smoke, the quantity of cigarettes that he chooses to smoke, and the manner in which he acquires cigarettes. Given these different pathways and the different price effect on each pathway, it is important to quantify the total impact of a cigarette price increase. To this end, the elasticity estimates produced from Tables 3,5 , and 6 can be used to quantify the total impact of a price change on cigarette consumption by teens as follows: Let $C / N$ represent total cigarette consumption per capita. $C / N$ can be rewritten as the sum of consumption 
by buyers $\left(C_{\text {buy }}\right)$ and bummers $\left(C_{\text {bum }}\right)$ divided by the total number of non-smokers $\left(N_{\text {non }}\right)$, bummers $\left(N_{\text {bum }}\right)$, and buyers $\left(N_{b u y}\right): \frac{C_{b u y}+C_{b u m}}{N_{n o n}+N_{b u m}+N_{b u y}}$. Taking derivatives with respect to price and converting to an elasticity by multiplying by $P N / C$, the total price elasticity of cigarette consumption can be written as:

$$
\varepsilon_{C}=\left[\varepsilon_{\rho, b u y}+\varepsilon_{c, b u y}\right] \frac{C_{b u y}}{C}+\left[\varepsilon_{\rho, b u m}+\varepsilon_{c, b u m}\right] \frac{C_{b u m}}{C} .
$$

Equation (20) shows that the price elasticity of consumption for all smokers $\left(\varepsilon_{C}\right)$ is simply a weighted sum of four elasticities. These four elasticities account for the fact that within each type of group (non-smoker, bummer, buyer), price changes will impact both the probability of being in the group $\left(\varepsilon_{\rho, b u y}\right.$ or $\left.\varepsilon_{\rho, b u m}\right)$ and the quantity smoked given group membership $\left(\varepsilon_{c, \text { buy }}\right.$ or $\left.\varepsilon_{c, b u m}\right)$. The weight on each individual elasticity is the share of total consumption by that group.

The elasticity estimates from Tables 3, 5, and 6 are used to calculate the total price elasticity for the two measures of cigarette consumption. The total price elasticity is -0.271 if the number of days smoked is the measure of cigarette consumption, and is -0.205 if the number of cigarettes smoked on days smoked is the measure of cigarette consumption. We caution that some estimates used in this calculation are statistically insignificant. However, all elasticity estimates (participation, frequency, and overall) are consistent with existing research. ${ }^{16}$ The immediate conclusion reached from these estimates is that while tax policy may not be an effective tool in reducing experimental smoking, it will reduce smoking by teenagers overall.

\footnotetext{
${ }^{16}$ Because elasticity calculations are inherently approximations, our method of distinguishing between different types of smokers should provide more accurate appoximations than studies that group different types together.
} 
Clearly, taxes are not the only policy that lawmakers can use to discourage teenage smoking and our theoretical model establishes the importance of controlling for such measures when estimating price effects. Our empirical analysis includes restrictions on smoking in the form of clean indoor air laws. As with the price and tax effects, our estimates show that bans have significant impact on smoking by buyers, but relatively little impact on bummers. The effect on the number of buyers is ambiguous. While restrictions placed on smoking in school do lower the probability of being a buyer relative to both non-smokers and bummers, they have no impact on the probability of being a buyer relative to just a bummer. Also recall that the theoretical model highlights the importance of controlling for anti-price based policies when calculating price and tax elasticities (Figure 7). Running the regressions without the ban information leads to differences in the price elasticity estimates as great as 14 percent.

In conclusion, this paper provides evidence that as prices rise, teenagers are less likely to be regular smokers who purchase cigarettes and are more likely to consume a smaller quantity of cigarettes obtained via the lending/borrowing market. In essence, higher prices induce a substitution away from buying towards bumming with the overall result that more teenagers will compete for fewer cigarettes that are available for borrowing. Thus, the net impact of higher prices is to reduce the total amount of cigarettes smoked. Restrictions on smoking such as clean indoor air laws will have a similar effect as these laws primarily affect the consumption of teens who buy cigarettes. As a result, policy makers who are interested in reducing cigarette consumption among teenagers should not be troubled by the fact that policies designed to reduce smoking have little impact on smoking initiation and 
experimentation. As long as higher taxes or restrictions on smoking reduce consumption by those who purchase cigarettes, the amount of cigarettes available for borrowing will decrease as the number of lenders decreases thus, producing an ancillary effect on smoking by initiators and experimenters. 


\section{Reference}

Bradley, MR, Green Jr., NM, Jones, DE, Lynn, M and McNeil, L. "Churches and Church Membership in the United States 1990." Atlanta: Glenmary Research Center, 1992.

Centers for Disease Control and Prevention. "Incidence of Initiation of Cigarette SmokingUnited States, 1965-1996." Morbidity and Mortality Weekly Report, 47:39, October 1998.

Centers for Disease Control and Prevention. "Trends in Cigarette Smoking Among High School Students-United States, 1991-1999." Morbidity and Mortality Weekly Report, 49:33, August 2000 .

Chaloupka, FJ and M Grossman. "Price, Tobacco Control Policies, and Youth Smoking." NBER Working Paper, No. 5740, September 1996.

Cragg, JG. "Some Statistical Models for Limited Dependent Variables with Application to the Demand for Durable Goods." Econometrica, 39:5, 829-844, 1971.

DeCicca, P, D Kenkel, and A Mathios. "Putting Out the Fires: Will Higher Taxes Reduce Youth Smoking?" Journal of Political Economy, 110:1, 144-169, February 2002.

Douglas, SM and G Hariharan. "The Hazard of Starting Smoking: Estimates from a Split Sample Duration Model." Journal of Health Economics, 13, 213-230, 1994.

Douglas, SM. "The Duration of the Smoking Habit." Economic Inquiry, 36:1, 49-64, 1998.

Emery, S, EA Gilpin, MM White, and JP Pierce. "How Adolescents Get Their Cigarettes" 
Implications for Policies on Access and Price." Journal of the National Cancer Institute, 91:2, 184-186, 1999.

Emery S, MM White and JP Pierce. "Does Cigarette Price Influence Adolescent Experimentation?" Journal of Health Economics, 20:2, 261-270, March 2001.

Evans, WN and LX Huang. "Cigarette Taxes and Teen Smoking: New Evidence from Panels of Repeated Cross Sections." Working Paper, Department of Economics, University of Maryland, 1998.

Forster, M and AM Jones. "The Role of Tobacco Taxes in Starting and Quitting Smoking: Duration Analysis of British Data." Working Paper, University of York, September 3, 1999.

Gratias EJ, DP Krowchuk, MR Lawless, and RH Durant. "Middle School Students' Sources of Acquiring Cigarettes and Requests for Proof of Age." Journal of Adolescent Health, 25, 276-283, 1999.

Gruber, J. "Youth Smoking in the U.S.: Prices and Policies." NBER Working Paper No. 7506, January 2000.

Huber, P. "The Behavior of Maximum-Likelihood Estimates Under Nonstandard Conditions." In Proceedings of the Fifth Berkeley Symposium in Mathematical Statistics, Vol. 1 Berkeley: University of California Press, 1967.

Lewit, EM, D Coate, and M Grossman. "The Effects of Government Regulations on Teenage Smoking." Journal of Law and Economics, 24, 545-569, 1981. 
Lucas K and B Lloyd. "Starting Smoking: Girls' Explanations of the Influence of Peers." Journal of Adolescence, 22, 647-655, 1999.

Smetters, K and J Gravelle. "The Exchange Theory of Teenage Smoking and the Counterproductiveness of Moderate Regulation." NBER Working Paper No. 8262, April 2001.

Tauras, JT, PM O'Malley, and LD Johnston. "Effects of Price and Access Laws on Teenage Smoking Initiation: A National Longitudinal Analysis." NBER Working Paper No. 8331, June 2001.

U.S. Department of Health and Human Services. "Preventing Tobacco Use Among Young People. A report of the Surgeon General.” Atlanta, Georgia: U.S. Department of Health and Human Services, Public Health Service, Centers for Disease Control and Prevention, National Center for Chronic Disease Prevention and Health Promotion, Office on Smoking and Health, 1994.

Wasserman, J, WG Manning, JP Newhouse, and JD Winkler. "The Effects of Excise Taxes and Regulations on Cigarette Smoking." Journal of Health Economics, 10, 43-64, 1991.

Wolfson M, JL Forster, AJ Claxton, and DM Murray. "Adolescent Smokers' Provision of Tobacco to Other Adolescents." American Journal of Public Health, 87, 649-651, April 1997. 
Figure 1: Price Effects on the Distribution of Adolescent Smokers

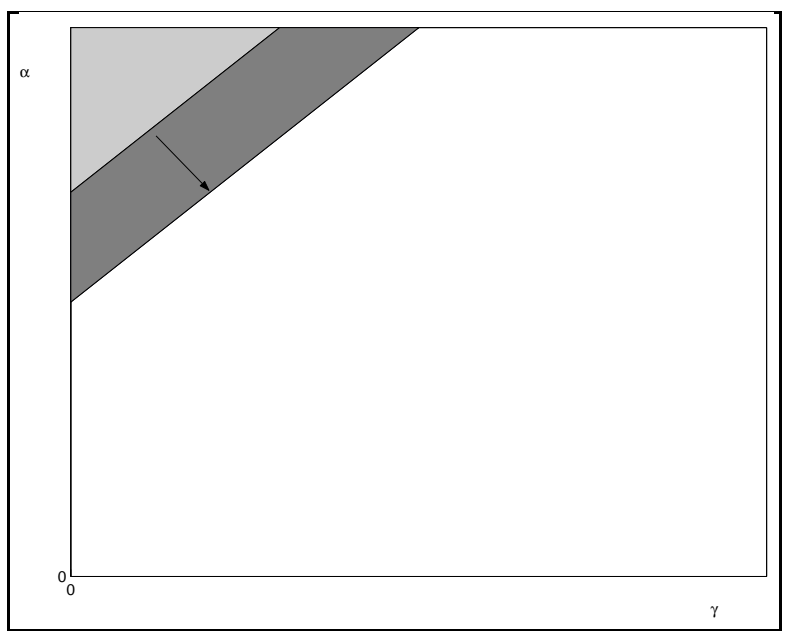

Figure 2: Lending Response to Price Changes

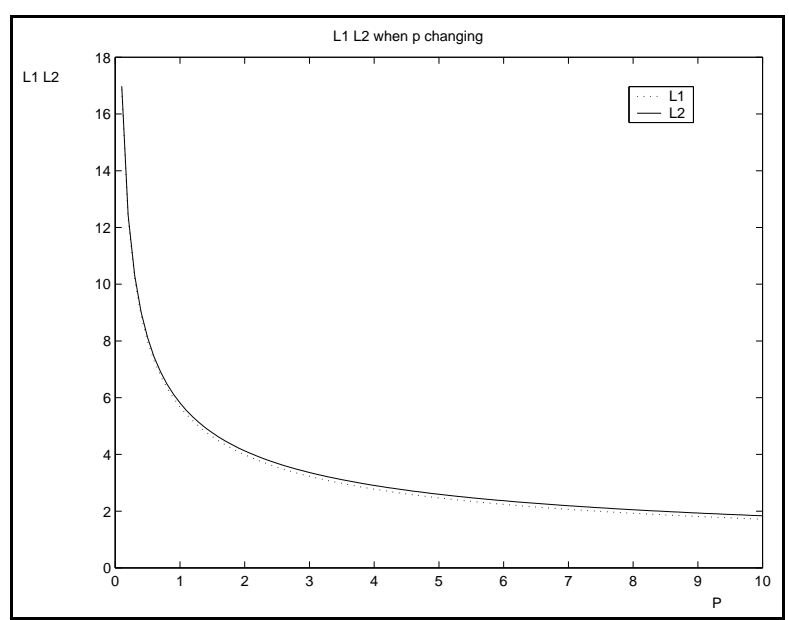


Figure 3: Consumption Response to Price Changes

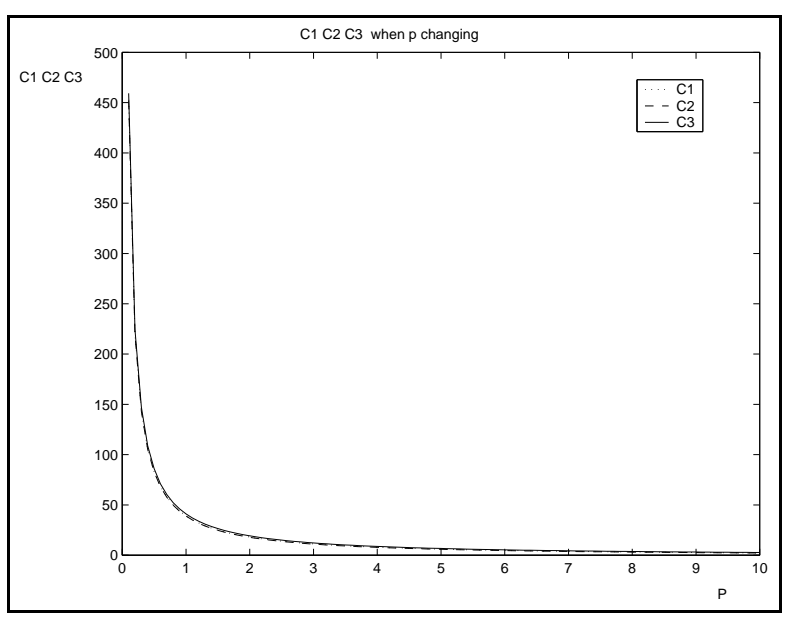

Figure 4: Consumption and Lending Response to Price Changes

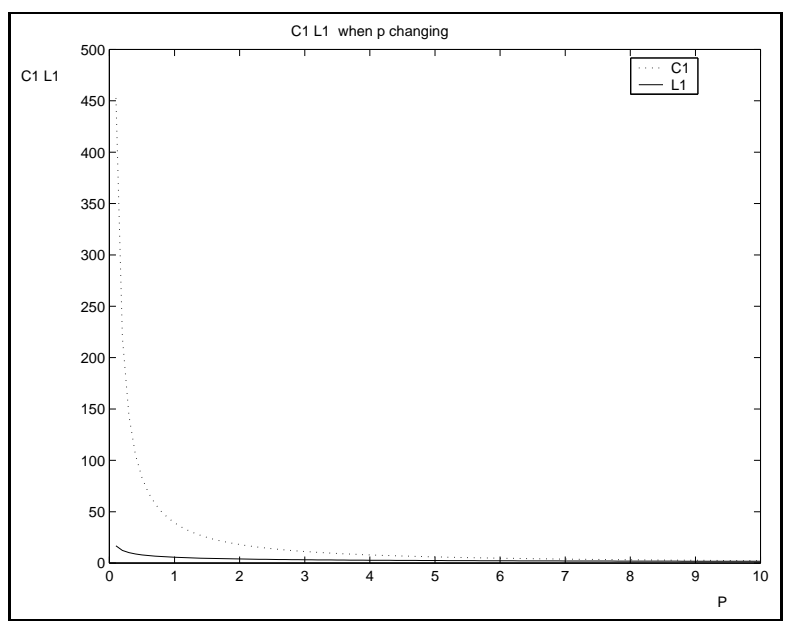


Figure 5: Consumption and Lending Price Elasticities

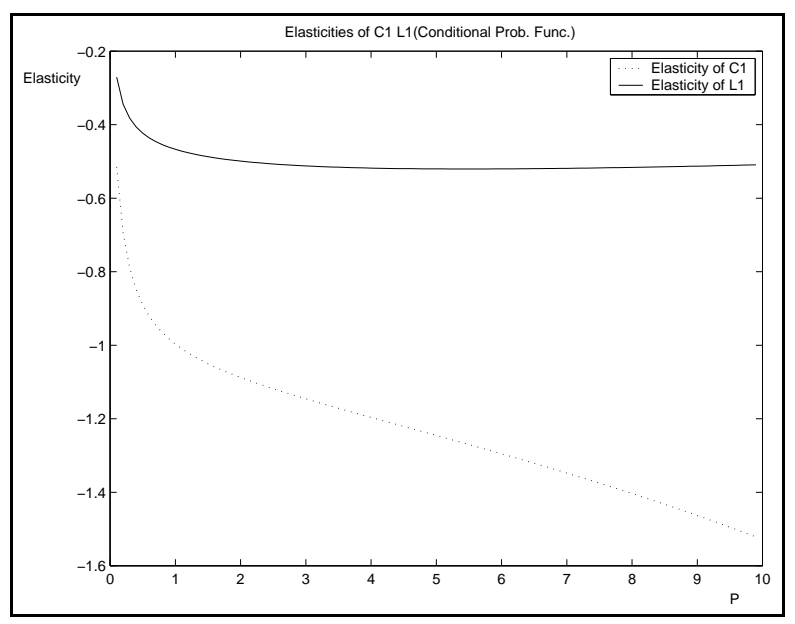

Figure 6: Consumption and Lending Response to Confiscation Policy

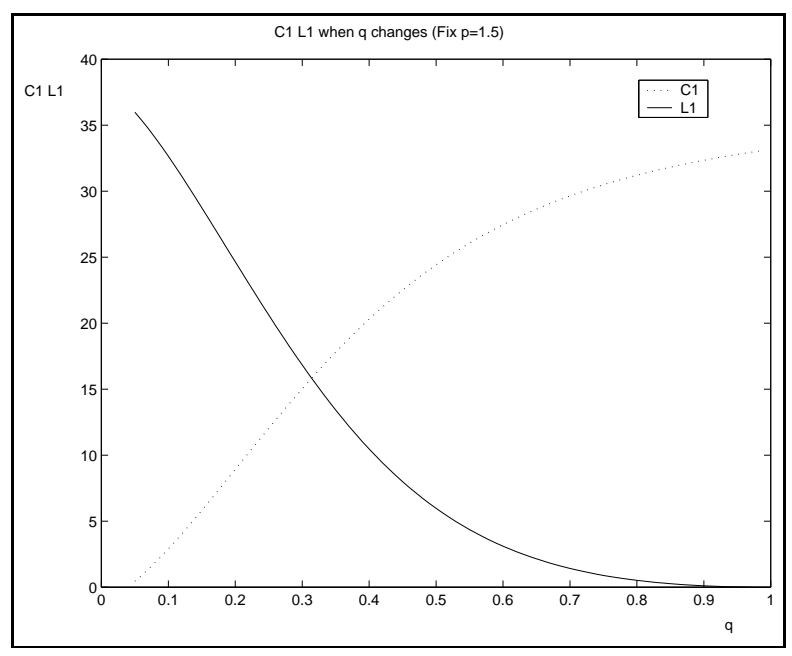


Figure 7: Effects of Confiscation Policy on Price Elasticity

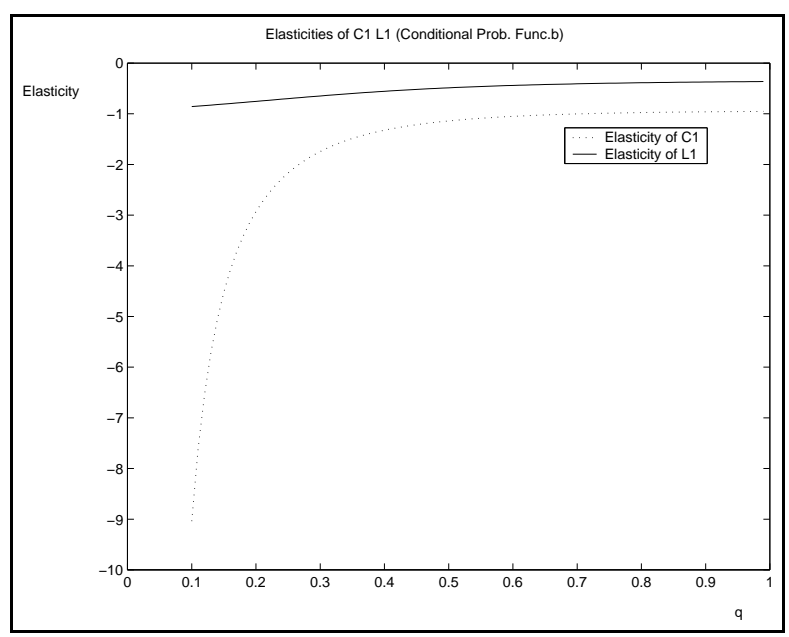

Figure 8: Substitution Effects on All Other Goods $(A)$

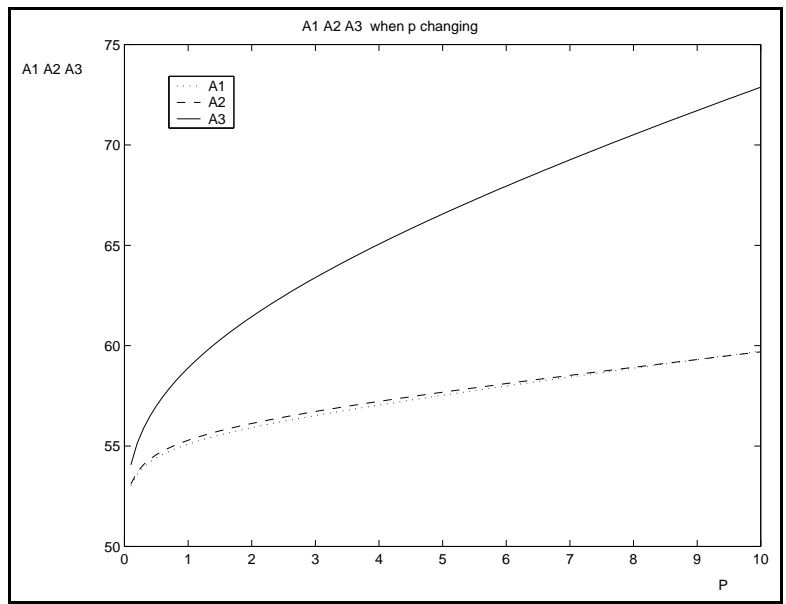


Table 1

Smoking of Buyers and Bummers

\begin{tabular}{lcc}
\hline Number of days smoked in the past month & $\begin{array}{c}\text { Percent of Buyers } \\
(\mathrm{N}=6,853)\end{array}$ & $\begin{array}{c}\text { Percent of Bummers } \\
(\mathrm{N}=3,791)\end{array}$ \\
\hline 1 or 2 & $10.51 \%$ & $51.33 \%$ \\
3 to 5 & $9.62 \%$ & $21.29 \%$ \\
6 to 9 & $8.01 \%$ & $11.21 \%$ \\
10 to 19 & $13.92 \%$ & $8.92 \%$ \\
20 to 30 & $14.69 \%$ & $3.77 \%$ \\
All 30 & $43.25 \%$ & $3.48 \%$ \\
Mean number of days & 19.88 & 5.81 \\
\hline Number of Cigarettes Smoked on Days Smoked & & $36.59 \%$ \\
\hline Less than 1 & $7.40 \%$ & $30.28 \%$ \\
1 & $10.91 \%$ & $30.36 \%$ \\
2 to 5 & $45.47 \%$ & $2.22 \%$ \\
6 to 10 & $19.52 \%$ & $0.37 \%$ \\
11 to 20 & $13.32 \%$ & $0.18 \%$ \\
Mean number of cigarettes & $3.37 \%$ & 1.82 \\
\hline
\end{tabular}


Table 2

Years Since First Smoked

\begin{tabular}{lcc}
\hline Years Since First Smoked & \% of Buyers & \% of Bummers \\
\hline 0 & 2.03 & 6.44 \\
1 & 9.11 & 17.90 \\
2 & 12.51 & 20.28 \\
3 & 16.57 & 16.24 \\
4 & 15.30 & 14.61 \\
5 & 14.55 & 9.38 \\
6 & 9.74 & 6.12 \\
7 & 9.32 & 4.52 \\
8 & 5.21 & 2.78 \\
9 & 4.15 & 1.15 \\
10 & 1.51 & 0.59 \\
\hline Mean Years Since Began Smoking & 4.36 & 3.19 \\
\hline
\end{tabular}


Table 3

Multinomial and Univariate Logits

\begin{tabular}{|c|c|c|c|c|c|}
\hline \multirow[b]{2}{*}{$\begin{array}{l}\text { All respondents } \\
(\mathrm{N}=37,513)\end{array}$} & \multicolumn{2}{|c|}{$\begin{array}{l}\text { Coefficient } \\
\text { (Z statistic) }\end{array}$} & \multicolumn{3}{|c|}{ Marginal Effects } \\
\hline & Bummer & Buyer & $\begin{array}{l}\text { Non- } \\
\text { smoker }\end{array}$ & Bummer & Buyer \\
\hline Price & $\begin{array}{l}0.229 \\
(1.55)\end{array}$ & $\begin{array}{l}0.023 \\
(0.19)\end{array}$ & $\begin{array}{l}-0.020 \\
(-1.04)\end{array}$ & $\begin{array}{r}0.021 \\
(1.54)\end{array}$ & $\begin{array}{l}-0.001 \\
(-0.04)\end{array}$ \\
\hline School Ban 1 & $\begin{array}{r}0.131 \\
(1.70)\end{array}$ & $\begin{array}{r}0.067 \\
(1.07)\end{array}$ & $\begin{array}{c}-0.018 \\
(-1.72)\end{array}$ & $\begin{array}{r}0.011 \\
(1.56)\end{array}$ & $\begin{array}{r}0.007 \\
(0.83)\end{array}$ \\
\hline School Ban 2 & $\begin{array}{c}-0.131 \\
(-0.90)\end{array}$ & $\begin{array}{c}-0.240 \\
(-2.02)\end{array}$ & $\begin{array}{c}0.038 \\
(2.04)\end{array}$ & $\begin{array}{c}-0.008 \\
(-0.66)\end{array}$ & $\begin{array}{r}-0.030 \\
(-2.05)\end{array}$ \\
\hline School Ban 3 & $\begin{array}{l}-0.131 \\
(-1.60)\end{array}$ & $\begin{array}{l}-0.149 \\
(-2.27)\end{array}$ & $\begin{array}{r}0.027 \\
(2.57)\end{array}$ & $\begin{array}{l}-0.010 \\
(-1.33)\end{array}$ & $\begin{array}{l}-0.018 \\
(-2.11)\end{array}$ \\
\hline Tax & $\begin{array}{l}0.203 \\
(1.15)\end{array}$ & $\begin{array}{l}-0.065 \\
(-0.46)\end{array}$ & $\begin{array}{l}-0.008 \\
(-0.33)\end{array}$ & $\begin{array}{c}0.020 \\
(1.23)\end{array}$ & $\begin{array}{r}-0.012 \\
(-0.64)\end{array}$ \\
\hline School Ban 1 & $\begin{array}{r}0.127 \\
(1.65)\end{array}$ & $\begin{array}{r}0.067 \\
(1.07)\end{array}$ & $\begin{array}{r}-0.017 \\
(-1.69)\end{array}$ & $\begin{array}{c}0.011 \\
(1.50)\end{array}$ & $\begin{array}{r}0.007 \\
(0.84)\end{array}$ \\
\hline School Ban 2 & $\begin{array}{l}-0.148 \\
(-1.03)\end{array}$ & $\begin{array}{l}-0.247 \\
(-2.09)\end{array}$ & $\begin{array}{c}0.040 \\
(2.17)\end{array}$ & $\begin{array}{l}-0.010 \\
(-0.77)\end{array}$ & $\begin{array}{l}-0.030 \\
(-2.10)\end{array}$ \\
\hline School Ban 3 & $\begin{array}{l}-0.133 \\
(-1.62)\end{array}$ & $\begin{array}{l}-0.148 \\
(-2.25)\end{array}$ & $\begin{array}{r}0.027 \\
(2.56)\end{array}$ & $\begin{array}{l}-0.010 \\
(-1.36)\end{array}$ & $\begin{array}{l}-0.017 \\
(-2.09)\end{array}$ \\
\hline $\begin{array}{l}\text { Current Smokers } \\
(\mathrm{N}=10,644)\end{array}$ & & & & & \\
\hline Price & -- & $\begin{array}{l}-0.329 \\
(-1.89)\end{array}$ & -- & $\overline{--}$ & $\begin{array}{l}-0.074 \\
(-1.89)\end{array}$ \\
\hline School Ban 1 & -- & $\begin{array}{c}-0.059 \\
(-0.65)\end{array}$ & -- & -- & $\begin{array}{l}-0.013 \\
(-0.65)\end{array}$ \\
\hline School Ban 2 & -- & $\begin{array}{c}-0.108 \\
(-0.62)\end{array}$ & -- & -- & $\begin{array}{l}-0.025 \\
(-0.62)\end{array}$ \\
\hline School Ban 3 & -- & $\begin{array}{l}-0.021 \\
(-0.22)\end{array}$ & -- & -- & $\begin{array}{l}-0.005 \\
(-0.22)\end{array}$ \\
\hline Tax & -- & $\begin{array}{l}-0.445 \\
(-2.14)\end{array}$ & -- & -- & $\begin{array}{l}-0.101 \\
(-2.14)\end{array}$ \\
\hline School Ban 1 & -- & $\begin{array}{l}-0.053 \\
(-0.58)\end{array}$ & -- & -- & $\begin{array}{l}-0.012 \\
(-0.58)\end{array}$ \\
\hline School Ban 2 & -- & $\begin{array}{l}-0.097 \\
(-0.56)\end{array}$ & -- & -- & $\begin{array}{l}-0.022 \\
(-0.56)\end{array}$ \\
\hline School Ban 3 & -- & $\begin{array}{c}-0.018 \\
(-0.18)\end{array}$ & -- & -- & $\begin{array}{l}-0.004 \\
(-0.18)\end{array}$ \\
\hline
\end{tabular}

Note: T-statistics are in parentheses. All models include school bans, age, gender, race, age greater than grade, age less than grade, seat belt, sports, religion, income, unemployment, year dummies, and region dummies. 
Table 4

Ordered Logits

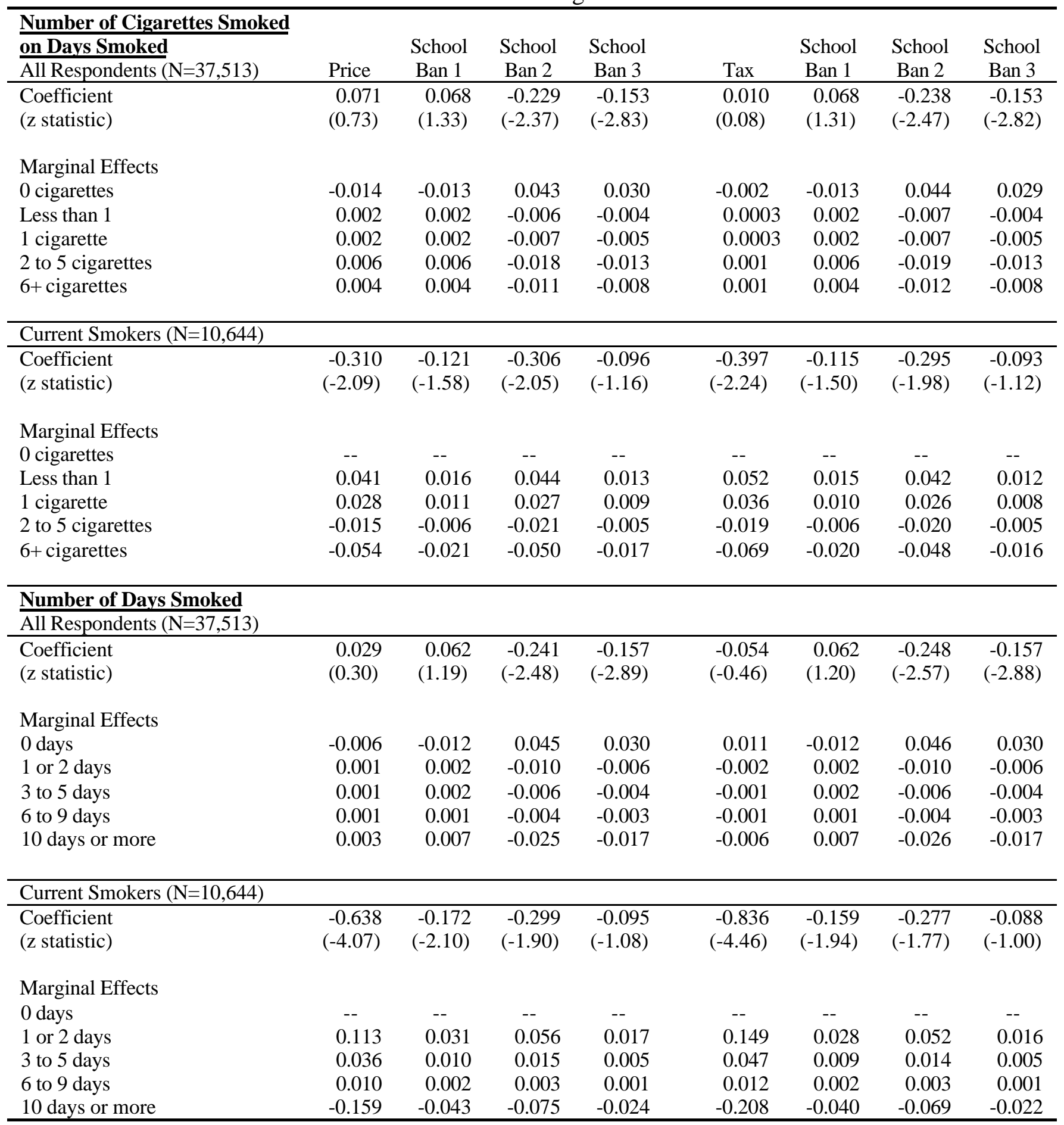

Note: T-statistics are in parentheses. All models include school bans, age, gender, race, age greater than grade, age less than grade, seat belt, sports, religion, income, unemployment, year dummies, and region dummies. For ordered logits, the statistical significance of the marginal effects generally corresponds to the statistical significance of the coefficients. 
Table 5

Number of Cigarettes Smoked on Days Smoked

\begin{tabular}{|c|c|c|c|c|c|c|}
\hline & $\begin{array}{c}\text { All Smokers } \\
(\mathrm{N}=10,644)\end{array}$ & $\begin{array}{c}\text { All Smokers } \\
(\mathrm{N}=10,644)\end{array}$ & $\begin{array}{c}\text { Buyers } \\
(\mathrm{N}=6,853) \\
\end{array}$ & $\begin{array}{c}\text { Buyers } \\
(\mathrm{N}=6,853)\end{array}$ & $\begin{array}{c}\text { Bummers } \\
(\mathrm{N}=3,791) \\
\end{array}$ & $\begin{array}{l}\text { Bummers } \\
(\mathrm{N}=3,791) \\
\end{array}$ \\
\hline Price & $\begin{array}{c}-0.888 \\
(-2.46)\end{array}$ & & $\begin{array}{l}-1.191 \\
(-2.46)\end{array}$ & & $\begin{array}{c}-0.001 \\
(-0.004)\end{array}$ & \\
\hline Tax & & $\begin{array}{l}-1.096 \\
(-2.54)\end{array}$ & & $\begin{array}{c}-1.510 \\
(-2.59)\end{array}$ & & $\begin{array}{c}0.150 \\
(0.47)\end{array}$ \\
\hline School ban 1 & $\begin{array}{l}-0.358 \\
(-1.93)\end{array}$ & $\begin{array}{r}-0.341 \\
(-1.84)\end{array}$ & $\begin{array}{l}-0.434 \\
(-1.75)\end{array}$ & $\begin{array}{l}-0.410 \\
(-1.66)\end{array}$ & $\begin{array}{l}-0.007 \\
(-0.05)\end{array}$ & $\begin{array}{l}-0.007 \\
(-0.05)\end{array}$ \\
\hline School ban 2 & $\begin{array}{l}-0.775 \\
(-2.14)\end{array}$ & $\begin{array}{l}-0.742 \\
(-2.06)\end{array}$ & $\begin{array}{l}-0.990 \\
(-1.99)\end{array}$ & $\begin{array}{l}-0.953 \\
(-1.92)\end{array}$ & $\begin{array}{l}-0.224 \\
(-0.86)\end{array}$ & $\begin{array}{l}-0.215 \\
(-0.83)\end{array}$ \\
\hline School ban 3 & $\begin{array}{c}-0.260 \\
(-1.31)\end{array}$ & $\begin{array}{r}-0.252 \\
(-1.27)\end{array}$ & $\begin{array}{l}-0.203 \\
(-0.77)\end{array}$ & $\begin{array}{l}-0.192 \\
(-0.73)\end{array}$ & $\begin{array}{r}-0.181 \\
(-1.19)\end{array}$ & $\begin{array}{c}-0.180 \\
(-1.19)\end{array}$ \\
\hline Age & $\begin{array}{r}0.440 \\
(11.69)\end{array}$ & $\begin{array}{r}0.441 \\
(11.71)\end{array}$ & $\begin{array}{c}0.252 \\
(4.87)\end{array}$ & $\begin{array}{c}0.253 \\
(4.90)\end{array}$ & $\begin{array}{c}0.021 \\
(0.76)\end{array}$ & $\begin{array}{r}0.021 \\
(0.74)\end{array}$ \\
\hline Female & $\begin{array}{c}-0.884 \\
(-9.77)\end{array}$ & $\begin{array}{c}-0.884 \\
(-9.77)\end{array}$ & $\begin{array}{c}-1.138 \\
(-9.25)\end{array}$ & $\begin{array}{l}-1.137 \\
(-9.25)\end{array}$ & $\begin{array}{l}-0.008 \\
(-0.13)\end{array}$ & $\begin{array}{l}-0.008 \\
(-0.12)\end{array}$ \\
\hline Black & $\begin{array}{r}-3.187 \\
(-25.04)\end{array}$ & $\begin{array}{r}-3.199 \\
(-25.15)\end{array}$ & $\begin{array}{r}-3.732 \\
(-20.97)\end{array}$ & $\begin{array}{r}-3.748 \\
(-21.07)\end{array}$ & $\begin{array}{l}-0.584 \\
(-6.42)\end{array}$ & $\begin{array}{l}-0.585 \\
(-6.44)\end{array}$ \\
\hline Nonwhite & $\begin{array}{r}-1.901 \\
(-16.82)\end{array}$ & $\begin{array}{r}-1.904 \\
(-16.91)\end{array}$ & $\begin{array}{c}-2.303 \\
(-15.06)\end{array}$ & $\begin{array}{r}-2.305 \\
(-15.11)\end{array}$ & $\begin{array}{r}-0.123 \\
(-1.48)\end{array}$ & $\begin{array}{r}-0.132 \\
(-1.58)\end{array}$ \\
\hline Age greater than grade & $\begin{array}{c}0.434 \\
(2.72)\end{array}$ & $\begin{array}{c}0.432 \\
(2.71)\end{array}$ & $\begin{array}{c}0.270 \\
(1.33)\end{array}$ & $\begin{array}{c}0.266 \\
(1.30)\end{array}$ & $\begin{array}{c}0.298 \\
(2.25)\end{array}$ & $\begin{array}{c}0.302 \\
(2.28)\end{array}$ \\
\hline Age less than grade & $\begin{array}{r}3.162 \\
(3.51)\end{array}$ & $\begin{array}{c}3.158 \\
(3.50)\end{array}$ & $\begin{array}{c}2.999 \\
(2.59)\end{array}$ & $\begin{array}{c}2.988 \\
(2.58)\end{array}$ & $\begin{array}{c}0.498 \\
(0.68)\end{array}$ & $\begin{array}{c}0.486 \\
(0.66)\end{array}$ \\
\hline Seat belt & $\begin{array}{r}-0.625 \\
(-17.32)\end{array}$ & $\begin{array}{r}-0.625 \\
(-17.33)\end{array}$ & $\begin{array}{r}-0.667 \\
(-14.05)\end{array}$ & $\begin{array}{r}-0.668 \\
(-14.06)\end{array}$ & $\begin{array}{l}-0.122 \\
(-4.35)\end{array}$ & $\begin{array}{l}-0.123 \\
(-4.38)\end{array}$ \\
\hline Sports & $\begin{array}{r}-0.380 \\
(-11.55)\end{array}$ & $\begin{array}{r}-0.379 \\
(-11.54)\end{array}$ & $\begin{array}{r}-0.443 \\
(-9.95)\end{array}$ & $\begin{array}{r}-0.442 \\
(-9.94)\end{array}$ & $\begin{array}{l}-0.054 \\
(-2.25)\end{array}$ & $\begin{array}{l}-0.054 \\
(-2.26)\end{array}$ \\
\hline Mormon & $\begin{array}{r}-0.161 \\
(-1.22)\end{array}$ & $\begin{array}{c}-0.160 \\
(-1.21)\end{array}$ & $\begin{array}{c}0.035 \\
(0.20)\end{array}$ & $\begin{array}{c}0.037 \\
(0.21)\end{array}$ & $\begin{array}{l}-0.305 \\
(-3.18)\end{array}$ & $\begin{array}{l}-0.302 \\
(-3.15)\end{array}$ \\
\hline Southern Baptist & $\begin{array}{c}-0.018 \\
(-1.50)\end{array}$ & $\begin{array}{l}-0.020 \\
(-1.62)\end{array}$ & $\begin{array}{r}-0.027 \\
(-1.63)\end{array}$ & $\begin{array}{r}-0.029 \\
(-1.77)\end{array}$ & $\begin{array}{l}-0.002 \\
(-0.26)\end{array}$ & $\begin{array}{l}-0.002 \\
(-0.18)\end{array}$ \\
\hline Protestant & $\begin{array}{l}-0.007 \\
(-1.26)\end{array}$ & $\begin{array}{l}-0.007 \\
(-1.28)\end{array}$ & $\begin{array}{r}-0.010 \\
(-1.37)\end{array}$ & $\begin{array}{r}-0.010 \\
(-1.37)\end{array}$ & $\begin{array}{l}-0.002 \\
(-0.53)\end{array}$ & $\begin{array}{l}-0.002 \\
(-0.53)\end{array}$ \\
\hline Catholic & $\begin{array}{r}-0.031 \\
(-3.84)\end{array}$ & $\begin{array}{r}-0.031 \\
(-3.96)\end{array}$ & $\begin{array}{c}-0.036 \\
(-3.34)\end{array}$ & $\begin{array}{l}-0.037 \\
(-3.45)\end{array}$ & $\begin{array}{l}-0.008 \\
(-1.32)\end{array}$ & $\begin{array}{c}-0.008 \\
(-1.38)\end{array}$ \\
\hline State per capita income & $\begin{array}{c}0.001 \\
(0.22)\end{array}$ & $\begin{array}{l}0.000002 \\
(0.00)\end{array}$ & $\begin{array}{c}0.002 \\
(0.46)\end{array}$ & $\begin{array}{r}0.001 \\
(0.24)\end{array}$ & $\begin{array}{c}0.001 \\
(0.18)\end{array}$ & $\begin{array}{l}0.0004 \\
(0.14)\end{array}$ \\
\hline Unemployment & $\begin{array}{c}0.226 \\
(3.28)\end{array}$ & $\begin{array}{c}0.227 \\
(3.29)\end{array}$ & $\begin{array}{c}0.321 \\
(3.41)\end{array}$ & $\begin{array}{c}0.323 \\
(3.43)\end{array}$ & $\begin{array}{l}-0.004 \\
(-0.08)\end{array}$ & $\begin{array}{l}-0.008 \\
(-0.15)\end{array}$ \\
\hline 1997 & $\begin{array}{r}-0.131 \\
(-0.99)\end{array}$ & $\begin{array}{l}-0.171 \\
(-1.31)\end{array}$ & $\begin{array}{l}-0.197 \\
(-1.12)\end{array}$ & $\begin{array}{r}-0.251 \\
(-1.44)\end{array}$ & $\begin{array}{c}0.176 \\
(1.77)\end{array}$ & $\begin{array}{c}0.176 \\
(1.78)\end{array}$ \\
\hline 1999 & $\begin{array}{c}0.412 \\
(1.58)\end{array}$ & $\begin{array}{r}-0.073 \\
(-0.46)\end{array}$ & $\begin{array}{c}0.632 \\
(1.81)\end{array}$ & $\begin{array}{r}-0.018 \\
(-0.08)\end{array}$ & $\begin{array}{r}-0.057 \\
(-0.29)\end{array}$ & $\begin{array}{l}-0.063 \\
(-0.53)\end{array}$ \\
\hline Northeast & $\begin{array}{c}0.859 \\
(1.90)\end{array}$ & $\begin{array}{c}0.925 \\
(2.06)\end{array}$ & $\begin{array}{c}1.224 \\
(1.98)\end{array}$ & $\begin{array}{c}1.310 \\
(2.14)\end{array}$ & $\begin{array}{r}-0.387 \\
(-1.19)\end{array}$ & $\begin{array}{r}-0.370 \\
(-1.14)\end{array}$ \\
\hline Midwest & $\begin{array}{c}0.101 \\
(0.25)\end{array}$ & $\begin{array}{c}0.181 \\
(0.45)\end{array}$ & $\begin{array}{c}0.151 \\
(0.27)\end{array}$ & $\begin{array}{c}0.255 \\
(0.46)\end{array}$ & $\begin{array}{c}-0.258 \\
(-0.88)\end{array}$ & $\begin{array}{l}-0.245 \\
(-0.85)\end{array}$ \\
\hline South & $\begin{array}{r}-0.355 \\
(-0.85) \\
\end{array}$ & $\begin{array}{r}-0.301 \\
(-0.73) \\
\end{array}$ & $\begin{array}{r}-0.133 \\
(-0.23) \\
\end{array}$ & $\begin{array}{r}-0.065 \\
(-0.12) \\
\end{array}$ & $\begin{array}{r}-0.549 \\
(-1.82) \\
\end{array}$ & $\begin{array}{r}-0.529 \\
(-1.77) \\
\end{array}$ \\
\hline Price/Tax Elasticity & -0.280 & -0.095 & -0.282 & -0.098 & -0.001 & 0.032 \\
\hline
\end{tabular}

Note: T-statistics in parentheses and intercept not shown. Ban 1 requires a restriction on smoking in schools which does not require a separate ventilated area, nor bans smoking. Ban 2 requires an enclosed, separate ventilated area or else smoking is banned entirely. Ban 3 prohibits smoking in schools. 
Table 6

Number of Days Smoked

\begin{tabular}{|c|c|c|c|c|c|c|}
\hline & $\begin{array}{c}\text { All Smokers } \\
(\mathrm{N}=10,644)\end{array}$ & $\begin{array}{c}\text { All Smokers } \\
(\mathrm{N}=10,644)\end{array}$ & $\begin{array}{c}\text { Buyers } \\
(\mathrm{N}=6,853)\end{array}$ & $\begin{array}{c}\text { Buyers } \\
(\mathrm{N}=6,853)\end{array}$ & $\begin{array}{l}\text { Bummers } \\
(\mathrm{N}=3,791)\end{array}$ & $\begin{array}{c}\text { Bummers } \\
(\mathrm{N}=3,791)\end{array}$ \\
\hline Price & $\begin{array}{l}-3.808 \\
(-4.23)\end{array}$ & & $\begin{array}{l}-3.892 \\
(-3.75)\end{array}$ & & $\begin{array}{l}-1.929 \\
(-1.96)\end{array}$ & \\
\hline Tax & & $\begin{array}{l}-5.162 \\
(-4.78)\end{array}$ & & $\begin{array}{l}-5.419 \\
(-4.34)\end{array}$ & & $\begin{array}{l}-2.213 \\
(-1.89)\end{array}$ \\
\hline School ban 1 & $\begin{array}{l}-1.060 \\
(-2.28)\end{array}$ & $\begin{array}{l}-0.985 \\
(-2.12)\end{array}$ & $\begin{array}{l}-1.082 \\
(-2.04)\end{array}$ & $\begin{array}{l}-1.003 \\
(-1.90)\end{array}$ & $\begin{array}{l}-0.483 \\
(-0.94)\end{array}$ & $\begin{array}{l}-0.449 \\
(-0.88)\end{array}$ \\
\hline School ban 2 & $\begin{array}{l}-1.547 \\
(-1.71)\end{array}$ & $\begin{array}{l}-1.430 \\
(-1.59)\end{array}$ & $\begin{array}{l}-1.514 \\
(-1.42)\end{array}$ & $\begin{array}{l}-1.415 \\
(-1.33)\end{array}$ & $\begin{array}{l}-0.653 \\
(-0.69)\end{array}$ & $\begin{array}{l}-0.567 \\
(-0.60)\end{array}$ \\
\hline School ban 3 & $\begin{array}{l}-0.212 \\
(-0.43)\end{array}$ & $\begin{array}{l}-0.172 \\
(-0.35)\end{array}$ & $\begin{array}{c}0.163 \\
(0.29)\end{array}$ & $\begin{array}{c}0.208 \\
(0.37)\end{array}$ & $\begin{array}{l}-0.646 \\
(-1.16)\end{array}$ & $\begin{array}{l}-0.628 \\
(-1.13)\end{array}$ \\
\hline Age & $\begin{array}{r}1.235 \\
(13.12)\end{array}$ & $\begin{array}{r}1.240 \\
(13.17)\end{array}$ & $\begin{array}{r}0.464 \\
(4.19)\end{array}$ & $\begin{array}{r}0.470 \\
(4.24)\end{array}$ & $\begin{array}{r}0.040 \\
(0.39)\end{array}$ & $\begin{array}{c}0.040 \\
(0.39)\end{array}$ \\
\hline Female & $\begin{array}{l}-1.475 \\
(-6.52)\end{array}$ & $\begin{array}{l}-1.475 \\
(-6.52)\end{array}$ & $\begin{array}{l}-1.029 \\
(-3.91)\end{array}$ & $\begin{array}{l}-1.028 \\
(-3.91)\end{array}$ & $\begin{array}{l}-0.579 \\
(-2.40)\end{array}$ & $\begin{array}{l}-0.581 \\
(-2.41)\end{array}$ \\
\hline Black & $\begin{array}{r}-7.141 \\
(-22.44)\end{array}$ & $\begin{array}{r}-7.191 \\
(-22.62)\end{array}$ & $\begin{array}{r}-6.893 \\
(-18.10)\end{array}$ & $\begin{array}{r}-6.946 \\
(-18.25)\end{array}$ & $\begin{array}{l}-1.778 \\
(-5.33)\end{array}$ & $\begin{array}{l}-1.805 \\
(-5.42)\end{array}$ \\
\hline Nonwhite & $\begin{array}{r}-4.792 \\
(-16.96)\end{array}$ & $\begin{array}{r}-4.782 \\
(-16.99)\end{array}$ & $\begin{array}{r}-4.964 \\
(-15.17)\end{array}$ & $\begin{array}{r}-4.947 \\
(-15.17)\end{array}$ & $\begin{array}{l}-1.136 \\
(-3.71)\end{array}$ & $\begin{array}{l}-1.153 \\
(-3.78)\end{array}$ \\
\hline Age greater than grade & $\begin{array}{l}1.290 \\
(3.23)\end{array}$ & $\begin{array}{r}1.275 \\
(3.20)\end{array}$ & $\begin{array}{r}0.525 \\
(1.20)\end{array}$ & $\begin{array}{c}0.511 \\
(1.17)\end{array}$ & $\begin{array}{l}1.076 \\
(2.22)\end{array}$ & $\begin{array}{l}1.080 \\
(2.23)\end{array}$ \\
\hline Age less than grade & $\begin{array}{c}6.498 \\
(2.89)\end{array}$ & $\begin{array}{c}6.482 \\
(2.88)\end{array}$ & $\begin{array}{r}1.952 \\
(0.79)\end{array}$ & $\begin{array}{l}1.906 \\
(0.77)\end{array}$ & $\begin{array}{l}7.361 \\
(2.72)\end{array}$ & $\begin{array}{r}7.367 \\
(2.72)\end{array}$ \\
\hline Seat belt & $\begin{array}{c}-1.502 \\
(-16.66)\end{array}$ & $\begin{array}{r}-1.500 \\
(-16.65)\end{array}$ & $\begin{array}{r}-1.239 \\
(-12.19)\end{array}$ & $\begin{array}{r}-1.238 \\
(-12.19)\end{array}$ & $\begin{array}{l}-0.687 \\
(-6.67)\end{array}$ & $\begin{array}{l}-0.688 \\
(-6.68)\end{array}$ \\
\hline Sports & $\begin{array}{r}-0.945 \\
(-11.50)\end{array}$ & $\begin{array}{r}-0.943 \\
(-11.48)\end{array}$ & $\begin{array}{r}-0.887 \\
(-9.31)\end{array}$ & $\begin{array}{l}-0.885 \\
(-9.29)\end{array}$ & $\begin{array}{l}-0.419 \\
(-4.75)\end{array}$ & $\begin{array}{l}-0.418 \\
(-4.74)\end{array}$ \\
\hline Mormon & $\begin{array}{l}-0.482 \\
(-1.45)\end{array}$ & $\begin{array}{l}-0.485 \\
(-1.46)\end{array}$ & $\begin{array}{c}0.102 \\
(0.27)\end{array}$ & $\begin{array}{c}0.099 \\
(0.26)\end{array}$ & $\begin{array}{l}-0.560 \\
(-1.59)\end{array}$ & $\begin{array}{l}-0.554 \\
(-1.58)\end{array}$ \\
\hline Southern Baptist & $\begin{array}{r}-0.082 \\
(-2.70)\end{array}$ & $\begin{array}{l}-0.092 \\
(-2.99)\end{array}$ & $\begin{array}{l}-0.087 \\
(-2.48)\end{array}$ & $\begin{array}{r}-0.098 \\
(-2.77)\end{array}$ & $\begin{array}{r}-0.063 \\
(-1.90)\end{array}$ & $\begin{array}{l}-0.065 \\
(-1.96)\end{array}$ \\
\hline Protestant & $\begin{array}{c}0.017 \\
(1.24)\end{array}$ & $\begin{array}{c}0.017 \\
(1.21)\end{array}$ & $\begin{array}{c}0.011 \\
(0.67)\end{array}$ & $\begin{array}{c}0.011 \\
(0.66)\end{array}$ & $\begin{array}{c}0.021 \\
(1.38)\end{array}$ & $\begin{array}{c}0.020 \\
(1.35)\end{array}$ \\
\hline Catholic & $\begin{array}{l}-0.069 \\
(-3.47)\end{array}$ & $\begin{array}{l}-0.072 \\
(-3.63)\end{array}$ & $\begin{array}{l}-0.079 \\
(-3.45)\end{array}$ & $\begin{array}{l}-0.082 \\
(-3.58)\end{array}$ & $\begin{array}{l}-0.016 \\
(-0.74)\end{array}$ & $\begin{array}{l}-0.018 \\
(-0.85)\end{array}$ \\
\hline State per capita income & $\begin{array}{c}0.011 \\
(1.18)\end{array}$ & $\begin{array}{c}0.008 \\
(0.83)\end{array}$ & $\begin{array}{c}0.023 \\
(2.08)\end{array}$ & $\begin{array}{c}0.020 \\
(1.77)\end{array}$ & $\begin{array}{c}0.002 \\
(0.21)\end{array}$ & $\begin{array}{l}0.0005 \\
(0.05)\end{array}$ \\
\hline Unemployment & $\begin{array}{r}0.057 \\
(0.33)\end{array}$ & $\begin{array}{r}0.069 \\
(0.40)\end{array}$ & $\begin{array}{l}-0.104 \\
(-0.52)\end{array}$ & $\begin{array}{l}-0.088 \\
(-0.44)\end{array}$ & $\begin{array}{r}0.017 \\
(0.09)\end{array}$ & $\begin{array}{c}0.013 \\
(0.07)\end{array}$ \\
\hline 1997 & $\begin{array}{r}-0.057 \\
(-0.17)\end{array}$ & $\begin{array}{l}-0.233 \\
(-0.71)\end{array}$ & $\begin{array}{l}-0.186 \\
(-0.49)\end{array}$ & $\begin{array}{l}-0.365 \\
(-0.98)\end{array}$ & $\begin{array}{c}0.283 \\
(0.77)\end{array}$ & $\begin{array}{c}0.194 \\
(0.54)\end{array}$ \\
\hline 1999 & $\begin{array}{c}2.176 \\
(3.33)\end{array}$ & $\begin{array}{c}0.108 \\
(0.28)\end{array}$ & $\begin{array}{c}2.300 \\
(3.07)\end{array}$ & $\begin{array}{c}0.190 \\
(0.42)\end{array}$ & $\begin{array}{c}1.113 \\
(1.55)\end{array}$ & $\begin{array}{c}0.054 \\
(0.13)\end{array}$ \\
\hline Northeast & $\begin{array}{l}1.630 \\
(1.44)\end{array}$ & $\begin{array}{c}1.871 \\
(1.67)\end{array}$ & $\begin{array}{c}2.097 \\
(1.59)\end{array}$ & $\begin{array}{c}2.340 \\
(1.78)\end{array}$ & $\begin{array}{l}-0.199 \\
(-0.17)\end{array}$ & $\begin{array}{l}-0.042 \\
(-0.04)\end{array}$ \\
\hline Midwest & $\begin{array}{l}-0.504 \\
(-0.49)\end{array}$ & $\begin{array}{l}-0.193 \\
(-0.19)\end{array}$ & $\begin{array}{l}-0.620 \\
(-0.52)\end{array}$ & $\begin{array}{l}-0.311 \\
(-0.26)\end{array}$ & $\begin{array}{l}-0.956 \\
(-0.89)\end{array}$ & $\begin{array}{l}-0.763 \\
(-0.72)\end{array}$ \\
\hline South & $\begin{array}{r}-1.230 \\
(-1.17)\end{array}$ & $\begin{array}{l}-1.053 \\
(-1.01)\end{array}$ & $\begin{array}{l}-0.441 \\
(-0.36)\end{array}$ & $\begin{array}{l}-0.270 \\
(-0.22)\end{array}$ & $\begin{array}{l}-1.370 \\
(-1.24)\end{array}$ & $\begin{array}{l}-1.232 \\
(-1.13)\end{array}$ \\
\hline Price/Tax Elasticity & -0.366 & -0.136 & -0.280 & -0.107 & -0.475 & -0.150 \\
\hline
\end{tabular}

Note: T-statistics in parentheses and intercept not shown. Ban 1 requires a restriction on smoking in schools which does not require a separate ventilated area, nor bans smoking. Ban 2 requires an enclosed, separate ventilated area or else smoking is banned entirely. Ban 3 prohibits smoking in schools. 